\title{
The BAD-BAX-Caspase-3 Cascade Modulates Synaptic Vesicle Pools via Autophagy
}

\author{
Qinhua Gu, ${ }^{1 *}$ Song Jiao, ${ }^{1 *}$ Kaizheng Duan, ${ }^{1 *}$ Ya-Xian Wang, ${ }^{2}$ Ronald S. Petralia, ${ }^{2}$ and Zheng $\mathrm{Li}^{1}$ \\ ${ }^{1}$ Section on Synapse Development Plasticity, National Institute of Mental Health, National Institutes of Health, Bethesda, Maryland 20892, and \\ ${ }^{2}$ Advanced Imaging Core, National Institute on Deafness and Other Communication Disorders, National Institutes of Health, Bethesda, Maryland \\ 20892
}

The BAD-BAX-caspase-3 cascade is a canonical apoptosis pathway. Macroautophagy ("autophagy" hereinafter) is a process by which organelles and aggregated proteins are delivered to lysosomes for degradation. Here, we report a new function of the BAD-BAX-caspase- 3 cascade and autophagy in the control of synaptic vesicle pools. We found that, in hippocampal neurons of male mice, the BAD-BAX-caspase-3 pathway regulates autophagy, which in turn limits the size of synaptic vesicle pools and influences the kinetics of activity-induced depletion and recovery of synaptic vesicle pools. Moreover, the caspase-autophagy pathway is engaged by fear conditioning to facilitate associative fear learning and memory. This work identifies a new mechanism for controlling synaptic vesicle pools, and a novel, nonapoptotic, presynaptic function of the BAD-BAX-caspase-3 cascade.

Key words: autophagy; fear conditioning; fear memory; synaptic vesicle

\section{Significance Statement}

Despite the importance of synaptic vesicles for neurons, little is known about how the size of synaptic vesicle pools is maintained under basal conditions and regulated by neural activity. This study identifies a new mechanism for the control of synaptic vesicle pools, and a new, nonapoptotic function of the BAD-BAX-caspase-3 pathway in presynaptic terminals. Additionally, it indicates that autophagy is not only a homeostatic mechanism to maintain the integrity of cells and tissues, but also a process engaged by neural activity to regulate synaptic vesicle pools for optimal synaptic responses, learning, and memory.

\section{Introduction}

Synaptic vesicles undergo exocyosis to release neurotransmitters when the presynaptic membrane is depolarized by action potentials. After exocytosis, vesicles are retrieved by endocytosis and recycled to form new synaptic vesicles (Sudhof, 2004). The number of synaptic vesicles at a synapse is an important factor determining synaptic strength, which is dynamically regulated during development and by experience (Goda and Stevens, 1998; Abbott and Regehr, 2004; Catterall and Few, 2008).

\footnotetext{
Received Apr. 23, 2020; revised Nov. 20, 2020; accepted Nov. 29, 2020

Author contributions: Q.G., S.J., K.D., Y.-X.W., and R.S.P. performed research; Q.G., S.J., K.D., and Z.L. analyzed data; S.J., K.D., and Z.L. edited the paper; Z.L. designed research; Z.L. wrote the first draft of the paper; Z.L. wrote the paper.

${ }^{*}$ Q.G., S.J., and K.D. contributed equally to this work.

The authors declare no competing financial interests.

This work was supported by National Institute of Mental Health/National Institutes of Health Z1A MH002881 to Z.L. and the National Institute on Deafness and Other Communication Disorders/National Institutes of Health (ZIC DC000081 to Imaging Core) Advanced Intramural Research Programs. We thank Dr. Heinz Arnheiter for intense discussion and critical reading of the manuscript; and Dr. Elizabeth J. Sherman for editing of the manuscript.

Correspondence should be addressed to Zheng Li at lizheng2@mail.nih.gov.

https://doi.org/10.1523/JNEUROSCI.0969-20.2020

Copyright $\odot 2021$ the authors
}

A stable, yet flexible, pool of synaptic vesicles is critical to ensure the reliability and adaptability of neural circuits. Although synaptic vesicles have been intensively studied, how their number is maintained and regulated remains largely unclear.

Emerging evidence suggests a role of macroautophagy ("autophagy" hereinafter) in the life cycle of synaptic vesicles. Rab26, a small GTPase enriched on synaptic vesicles, also localizes to autophagosomes, and its overexpression induces large vesicular clusters containing synaptic-vesicle and lysosomal proteins (Binotti et al., 2015); activation of autophagy by inhibitors of mammalian target of rapamycin (mTOR) reduces the number of synaptic vesicles (Hernandez et al., 2012).

Autophagy is a cellular process through which proteins and organelles are delivered to lysosomes for degradation. Autophagy removes defective proteins and organelles under physiological conditions and serves as a prosurvival mechanism by recycling nonessential cellular constituents under cellular stress, such as starvation and growth factor withdrawal (Levine and Kroemer, 2008; Moreau et al., 2010; Galluzzi et al., 2014). It begins with the formation of the isolation membrane or phagophore, which sequesters the cargo. The phagophore expands to form an autophagosome, a double-membrane structure, which fuses with 
lysosomes to form an autolysosome where cargo degradation occurs. Target of rapamycin (TOR) is a key regulator of autophagy induction. In mammals, TOR complex 1 (mTORC1) inhibits autophagy by phosphorylating ULK1/2 (Unc-51-like kinase) and Atg13. Consequently, mTORC1 inhibition promotes the initiation of autophagy (Hara et al., 2008; Ganley et al., 2009; Jung et al., 2009).

The BAD-BAX-caspase- 3 cascade is a canonical apoptosis pathway and has a nonapoptotic function in long-term synaptic depression at the postsynaptic site ( $\mathrm{Li}$ et al., 2010; Jiao and Li, 2011). Here, we show that, at the presynaptic site of hippocampal neurons, the BAD-BAX-caspase-3 pathway inhibits autophagy, which in turn controls the size of synaptic vesicle pools. Moreover, the regulation of autophagy by caspase- 3 influences activity-induced depletion, and recovery of synaptic vesicle pools and facilitates learning and memory.

\section{Materials and Methods}

KO mice, DNA constructs, and reagents. BAD KO mice were generously provided by Nika N. Danial (Harvard University). BAX KO, caspase-3 KO, CA3-specific Cre, and CA1-specific Cre mice were purchased from The Jackson Laboratory. Floxed Atg5 and Atg7 mice were purchased from RIKEN BioResource Center. The following constructs were obtained as gifts: EGFP-Rab5, EGFP-Rab7, EGFP-Rab9 (Juan Bonifacino, National Institute of Child Health and Human Development, National Institutes of Health), and EGFP-Rab11 (James Goldenring, Vanderbilt University). Annealed oligos containing Atg5 (GGCTCACTTTATGTCATGT) and Beclin-1 (CAATTTGGCACGAT CAATA) siRNAs were inserted into the pSuper vector. The full-length cDNAs of Atg5 and Beclin-1 were inserted into the GW1 vector. The following reagents were obtained commercially: anti-caspase-3 (9665), anti-cleaved caspase-3 (9661), anti-Beclin-1 (3738), anti-Atg3 (3415), anti-Atg4B (5299), and anti-Atg7 (2631) antibody from Cell Signaling Technology; anti-Atg5 (NB110-53818), anti-Atg9A (NB110-56893), and anti-LC3 (NB100-2220) antibody from Novus Biologicals; anti-Actin (A4700) and anti- $\alpha$-tubulin (T6074) antibody from Sigma Millipore; anti-HA antibody (Covance, MMS-101P), anti-Bassoon antibody (Assay Designs, VAM-PS003), anti-Synaptotagmin1 luminal domain (Synaptic Systems, 105221), anti- $\beta$-Gal antibody (MP, 55976), rapamycin and chloroquine (CQ) from Sigma Millipore; and DEVD-fmk (ABD Bioquest), DEVD-biotin (R\&D Systems), avidin (Roche Diagnostics), NeutrAvidin conjugated with Oregon Green 488 (Invitrogen). The HEK293 cell line was purchased from ATCC.

Neuronal and glial cultures. Primary cortical cultures were prepared from embryonic day (E) 18-19 mouse embryos. Neurons were seeded on coverslips or plates coated with poly-D-lysine $(30 \mu \mathrm{g} / \mathrm{ml})$ at a density of $\sim 40,000$ cells $/ \mathrm{cm}^{2}$. Cultures were grown in Neurobasal medium (Thermo Fisher Scientific) supplemented with 2\% B27 (Thermo Fisher Scientific) and 1\% GlutaMax (Thermo Fisher Scientific). Ara-C was applied to neuronal cultures to suppress glial cell growth for testing Atg protein expression. For glial cell cultures, dissociated hippocampal cells from mouse embryos (E18-E19) were cultured in DMEM and harvested after the second pass.

Acute hippocampal slices. Mice 2-3 weeks of age were anesthetized by isoflurane overdose followed by decapitation. The brain was placed in ice-cold ACSF, pH 7.4, gassed with $95 \% \mathrm{O}_{2} / 5 \% \mathrm{CO}_{2}$, which is composed of the following (in mM): $124 \mathrm{NaCl}, 3 \mathrm{KCl}, 26 \mathrm{NaHCO}_{3}, 1.25 \mathrm{NaH}_{2} \mathrm{PO}_{4}$, $2.5 \mathrm{CaCl}_{2}, 1.3 \mathrm{MgSO}_{4}$, and $10 \mathrm{D}$-glucose. Transverse hippocampal slices ( $350 \mu \mathrm{m}$ thick) were prepared in ice-chilled, oxygenated ACSF with a vibratome (Leica Microsystems). The CA3 region of the hippocampus was removed surgically. Hippocampal slices were recovered in ACSF at $30^{\circ} \mathrm{C}$ for $30 \mathrm{~min}$, then at room temperature for $30 \mathrm{~min}$ before being transferred to the recording chamber.

Hippocampal slice culture. Hippocampal slice cultures were prepared from 6- to 8-day-old mice. After decapitation, the brain was placed immediately in the cold cutting solution composed of the following (in $\mathrm{mm})$ : 238 sucrose, $2.5 \mathrm{KCl}, 26 \mathrm{NaHCO}_{3}, 1 \mathrm{NaH}_{2} \mathrm{PO}_{4}, 5 \mathrm{MgCl}_{2}, 11 \mathrm{D}$ - glucose, and $1 \mathrm{CaCl}_{2}$. Hippocampal slices $(350 \mu \mathrm{m})$ were cut with a vibratome (Leica Microsystems) and placed on semipermeable membrane inserts (Millipore) in a 6-well plate containing culture medium (78.8\% minimum essential medium, 20\% heat-inactivated horse serum, 25 mм HEPES, $10 \mathrm{~mm}$ D-glucose, $26 \mathrm{~mm} \mathrm{NaHCO}_{3}, 2 \mathrm{~mm} \mathrm{CaCl}_{2}, 2 \mathrm{~mm}$ $\mathrm{MgSO}_{4}, 0.0012 \%$ ascorbic acid, $1 \mu \mathrm{g} / \mathrm{ml}$ insulin; $\mathrm{pH} 7.3 ; 320-330 \mathrm{mOsm}$ ). The medium was changed every $2 \mathrm{~d}$. No antibiotics were used. Neurons were biolistically transfected using a gene gun (Helios Gene-gun system, Bio-Rad) at DIV 13-14. Electrophysiological recordings were performed at $2 \mathrm{~d}$ after transfection.

Electrophysiology. Using the standard method, hippocampal slices were perfused with ACSF (bubbled with $95 \% \mathrm{O}_{2} / 5 \% \mathrm{CO}_{2} ; 30^{\circ} \mathrm{C}$ ) at the rate of $2 \mathrm{ml} / \mathrm{min}$. A stimulating electrode was placed on the stratum radiatum in the CA2 area. For whole-cell recordings, $100 \mu \mathrm{m}$ bicuculline was added to the ACSF to block $\mathrm{GABA}_{\mathrm{A}}$ receptors. The patch pipette (4-7 $\mathrm{M} \Omega$ ) solution is composed of the following (in $\mathrm{mm}$ ): 130 cesium methanesulfonate, $8 \mathrm{NaCl}$, $4 \mathrm{Mg}$-ATP, $0.3 \mathrm{Na}$-GTP, 0.5 EGTA, 10 HEPES, and 5 QX-314 at pH 7.3. For whole-cell recordings in cultured hippocampal slices, $2 \mu \mathrm{M}$ 2-chloroadenosine was added to the ACSF to prevent bursting. EPSCs of CA1 pyramidal cells were recorded at $-70 \mathrm{mV}$. Pairedpulse facilitation was measured as the ratio of the second to the first EPSC amplitude evoked by two equivalent stimuli at an interpulse interval of $50 \mathrm{~ms}$. mEPSCs were acquired at $-70 \mathrm{mV}$ and averaged from a 10 min recording. For sucrose-induced readily releasable pool (RRP) depletion, hypertonic solution ( $500 \mathrm{~mm}$ sucrose in ACSF) was applied locally to the recorded region for $3 \mathrm{~s}$. The size of readily releasable synaptic vesicle pools was estimated using the method described by Dobrunz and Stevens (1997). Briefly, for single-patch experiments, EPSCs in the voltage-clamped neuron were evoked by using minimal stimulations (20-40 trains of pulses at 2 min intervals), which stimulates putative one axon fiber that makes one synapse on the voltage-clamped neuron. Each train of pulse consists of 40 stimuli at $10 \mathrm{~Hz}$. For double-patch experiments, pairs of neighboring neurons, one in the current mode and the other in the voltage mode, were patch-clamped. EPSCs in the voltage-clamped neuron were elicited by repetitively evoking action potentials in the current-clamped neuron with 20-40 trains of current pulses (40 stimuli, $10 \mathrm{~Hz}$ ) at $2 \mathrm{~min}$ intervals. The potency, latency, and kinetics of evoked EPSCs were monitored online and analyzed offline to ensure that only those resulting from single synaptic connections were included in RRP analysis. The release probability was plotted against the stimulus number, and the decay phase of the curve was fit with a single exponential to obtain the decay constant. The functional pool size of synaptic vesicles was calculated as the total number of quantal release from the first stimulus to three decay constants after the maximal release probability. To measure the depletion and recovery rate of synaptic vesicle pools, fEPSPs in the CA1 region evoked by a train of 150 pulses at $10 \mathrm{~Hz}$ were recorded both during and 250 $5000 \mathrm{~ms}$ after stimulation. The depletion rate was obtained by fitting the slopes of evoked fEPSPs during depletion with a monoexponential function, while the recovery rate was assessed by fitting the slopes of evoked fEPSPs with a linear function. Series resistance and input resistance were monitored online and analyzed with the Clampex program offline. Only cells with a series resistance of $<25 \mathrm{~m} \Omega$ and a $<10 \%$ drift in both series and input resistance during the recording period were included.

Electron microscopy. After anesthesia and decapitation, the brain was taken out and sliced into $350 \mu \mathrm{m}$ sections in icy ACSF. Brain sections were fixed in $2 \% \mathrm{PFA} / 2 \%$ glutaraldehyde in $0.1 \mathrm{M} \mathrm{PB}$ at room temperature for $30 \mathrm{~min}$, washed 3 times in cold $\mathrm{PB}\left(4^{\circ} \mathrm{C}\right)$, and then incubated in $\mathrm{PB}$ at $4^{\circ} \mathrm{C}$ overnight. After washing in $0.1 \mathrm{M}$ cacodylate buffer, samples were postfixed in $1 \%$ osmium tetroxide and dehydrated through a graded ethanol series (including 1\% uranyl acetate in 50\% ethanol). After removing residual ethanol in propylene oxide, tissues were embedded in epon and polymerized at $64^{\circ} \mathrm{C}$ (Petralia and Wenthold, 1999). Thin sections $(75 \mathrm{~nm})$ were cut on a Leica Microsystems Ultracut ultramicrotome, and examined in a JEOL JSM-1010 or JEM-2100 transmission electron microscope (Peabody). The micrographs of randomly selected regions containing synapses were taken with an AMT or Gatan digital camera. 
Caspase- 3 activity assay. Hippocampal neurons were fixed in PBS containing $4 \% \mathrm{PFA} / 4 \%$ sucrose for $15 \mathrm{~min}$ at room temperature and incubated with avidin at $4^{\circ} \mathrm{C}$ overnight. After blocking avidin with biotin for $2 \mathrm{~h}$ at room temperature, cells were stained with DEVD-biotin at $4^{\circ} \mathrm{C}$ overnight, followed by incubation with NeutrAvidin conjugated with Oregon Green 488 for $1 \mathrm{~h}$ at room temperature.

Live labeling of synaptic vesicles. Neurons were incubated with the antibody against the luminal domain of synaptotagmin 1 for $15 \mathrm{~min}$ at $37^{\circ} \mathrm{C}$. At various times following incubation with the synaptotagmin antibody, cells were fixed in PBS containing 4\% PFA/4\% sucrose for $15 \mathrm{~min}$ at room temperature. Fixed cells were incubated with the light chain 3 (LC3) or Rab antibody at $4^{\circ} \mathrm{C}$ overnight, followed by incubation at room temperature with fluorophore-conjugated (for LC3) or HRP-conjugated (for Rab) secondary antibodies for $1 \mathrm{~h}$, and then with fluorophore-labeled tyramide for $15 \mathrm{~min}$.

Image acquisition and image analysis. Images were acquired with a Carl Zeiss LSM510 confocal microscope with a $63 \times$ (NA 1.4) objective. To analyze colocalization of Rab proteins and LC3 or synaptotagmin, images were taken from axons $100-200 \mu \mathrm{m}$ away from the cell body. Velocity software was used to measure fluorescence intensity and the volume of colocalization. All image acquisition and image analysis were done blindly to the treatment.

Behavioral tests. All animal procedures followed the National Institutes of Health Guidelines Using Animals in Intramural Research and were approved by the National Institute of Mental Health Animal Care and Use Committee. Two to 4 mice were housed in a cage kept in a temperature $\left(22 \pm 2^{\circ} \mathrm{C}\right)$ and humidity (35\%-60\%) controlled environment under a $12 \mathrm{~h}$ light/dark cycle. Male $(\mathrm{C} 57 \mathrm{BL} / 6) \operatorname{Atg} 5^{\text {flox/flox }} \mathrm{Cre}^{+}$ (KO) mice and their WT (Atg5 ${ }^{\text {flox/flox }} \mathrm{Cre}^{-}$) littermates of 9- to 10 -week old were tested for behavior during the light cycle of the animal as described previously (Liu et al., 2014). In the open field test, mice were placed in the center of a chamber $(40 \times 40 \times 40 \mathrm{~cm})$ and allowed to freely explore the arena for $30 \mathrm{~min}$. In the light/dark box test, mice were placed in the center of a test box $(46 \times 27 \times 30 \mathrm{~cm}$, divided into a dark and a light compartment) and then monitored for $6 \mathrm{~min}$. The elevated zero maze $(60 \mathrm{~cm}$ in diameter, CleverSys) is divided into four equal sections (two open and two enclosed). Mice were placed in the middle of one open section to begin the test and left in the maze for $6 \mathrm{~min}$. Mice were videotaped during the open field, light/dark box, and elevated zero maze test, and their behavior was analyzed using the TopScan software (CleverSys). For fear conditioning, mice were placed in the test chamber for $2 \mathrm{~min}$, then exposed to 5 (for fear memory test) or 10 (for immunoblotting) conditioned stimuli (CS; a $6000 \mathrm{~Hz}, 85 \mathrm{~dB}$ tone lasting for $30 \mathrm{~s}$ ) coterminated with the unconditioned stimulus (US, $0.75 \mathrm{~mA}$ of continuous $0.5 \mathrm{~s}$ foot shock). At $30 \mathrm{~s}$ after foot shock, the mouse was either killed for immunoblotting or returned to its home cage. At $1 \mathrm{~d}$ after fear conditioning, mice were placed in a novel chamber and received CS (a $6000 \mathrm{~Hz}, 85 \mathrm{~dB}$ tone lasting for $2 \mathrm{~min}$ ) $1 \mathrm{~min}$ later. Freezing was defined as complete immobility of the animal, except for respiratory movement. Mice were subject to either a battery of behavioral tests in the order of open field, light/dark box, elevated zero maze and fear conditioning, or only the fear conditioning test. The open field test is a commonly used test for locomotion and anxiety-like behavior (Crawley, 1999). The light/dark box test is commonly used to test for anxiety-like behavior (Hascoet and Bourin, 1998; Bourin and Hascoet, 2003). Foot shock is a standard procedure used in fear conditioning (Curzon et al., 2009).

Statistical analysis. The data were first tested for normality using Shapiro-Wilk test and equal variance using Levene's test. To test for differences among more than two groups, normally distributed data with equal variance were analyzed using one-way ANOVA and then post hoc comparison between two groups; data that did not pass the normality and equal variance test were analyzed using Kruskal-Wallis one-way ANOVA on ranks and then post hoc comparison between two groups. To compare two groups, two-tailed Student's $t$ test (for normally distributed data) or Mann-Whitney $U$ test (for non-normally distributed data) was used for statistical analysis. $p<0.05$ was considered significant.

\section{Results}

The presynaptic function is impaired in BAD, BAX, and caspase- $3 \mathrm{KO}$ mice

We previously showed that activation of the BAD-BAX-caspase3 cascade in postsynaptic neurons is essential for the induction of LTD of synaptic transmission (Li et al., 2010; Jiao and Li, 2011). To test whether this pathway also regulates other synaptic properties, we examined mEPSCs in acute hippocampal slices prepared from WT and BAD, BAX, or caspase- $3 \mathrm{KO}$ mice (16-19d of age). Notably, the frequency of mEPSCs recorded from CA1 neurons with whole-cell patch at a holding potential of $-70 \mathrm{mV}$ was greatly reduced in $\mathrm{KO}$ cells (WT: $1.00 \pm 0.09 \mathrm{~Hz}$; BAD KO: $0.59 \pm 0.09 \mathrm{~Hz}, p=0.004$ for $\mathrm{KO}$ vs WT; BAX KO: $0.51 \pm 0.09 \mathrm{~Hz}, p<0.001$ for $\mathrm{KO}$ vs WT; caspase-3 KO: $0.55 \pm 0.07 \mathrm{~Hz}, p=0.005$ for $\mathrm{KO}$ vs WT; $n=30$ cells from 5 mice for each group; one-way ANOVA on ranks was used for comparison across groups, $\mathrm{H}_{3}=22.485$, $p<0.001$; Tukey's test was used for post hoc analysis; Fig. $1 A)$. By contrast, the amplitude of mEPSCs was comparable in WT and KO cells (WT: $17.89 \pm 0.89 \mathrm{pA}$; BAD KO: $16.63 \pm 0.85 \mathrm{pA}$; BAX KO: $17.92 \pm 0.76 \mathrm{pA}$; caspase-3 KO: $17.50 \pm 0.80 \mathrm{pA} ; n=30$ cells from 5 mice for each group; oneway ANOVA on ranks was used for statistical analysis, $\mathrm{H}_{3}=$ $2.734, p=0.434$; Fig. $1 A$ ).

mEPSC amplitude correlates with the number of neurotransmitter receptors at the postsynaptic site (Stevens, 1993). Indistinguishable mEPSC amplitude in WT and KO cells is consistent with our previous report that AMPAR number is intact in the KO mice (Li et al., 2010; Jiao and Li, 2011). The reduction of mEPSC frequency may result from altered presynaptic release. To test this possibility, we analyzed pairedpulse ratio (PPR), which negatively correlates with presynaptic release probability (Dobrunz and Stevens, 1997; Zucker and Regehr, 2002). EPSCs of CA1 neurons were elicited by pairs of pulses delivered to the Schaffer collateral pathway at an interpulse interval of 25-200 ms and measured by whole-cell patch recording at a holding potential of $-70 \mathrm{mV}$. PPR (the ratio of the second to the first EPSC amplitude) was increased in $\mathrm{KO}$ neurons [25 ms: $p=0.022$ (one-way ANOVA, $F_{(3,43)}=3.551$ ), Student-Newman-Keuls method for post hoc analysis $(p=0.025$ for WT vs BAD KO, $p=0.017$ for WT vs BAX KO, $p=0.044$ for WT vs caspase-3 KO); $50 \mathrm{~ms}: p=0.039$ (one-way ANOVA on ranks, $\left.\mathrm{H}_{3}=8.355\right)$, Student-Newman-Keuls method for post $h o c$ analysis $(p=0.041$ for WT vs BAD KO, $p=0.01$ for WT vs $\mathrm{BAX} \mathrm{KO}, p<0.001$ for WT vs caspase-3 KO); one-way ANOVA on ranks for $75 \mathrm{~ms}\left(\mathrm{H}_{3}=7.106, p=0.069\right), 100 \mathrm{~ms}$ $\left(\mathrm{H}_{3}=5.619, p=0.132\right), 150 \mathrm{~ms}\left(\mathrm{H}_{3}=4.754, p=0.191\right), 200 \mathrm{~ms}$ $\left(\mathrm{H}_{3}=4.605, p=0.203\right)$; Fig. $\left.1 B\right]$. Since PPR is inversely correlated with presynaptic release probability, these findings indicate that presynaptic release probability decreased in the $\mathrm{KO}$ mice. In line with this, EPSCs evoked by high-intensity stimulation of the Schaffer collateral pathway also decreased in BAD, $\mathrm{BAX}$, and caspase-3 KO mice [one-way ANOVA on ranks was used for comparison across groups: $\mathrm{H}_{3}=3.569, p=0.312$ for $25 \mathrm{~mA} ; \mathrm{H}_{3}=12.762, p=0.005$ for $50 \mathrm{~mA} ; \mathrm{H}_{3}=17.870, p<0.001$ for $75 \mathrm{~mA} ; \mathrm{H}_{3}=13.532, p=0.004$ for $100 \mathrm{~mA}$; Dunn's method was used for post hoc analysis for $50 \mathrm{~mA}(p=0.181$ for WT vs BAD KO, $p=0.003$ for WT vs BAX KO, $p=0.347$ for WT vs caspase-3 KO), $75 \mathrm{~mA}(p=0.022$ for WT vs BAD KO, $p<0.001$ for WT vs BAX $\mathrm{KO}, p=0.026$ for WT vs caspase- $3 \mathrm{KO}), 100 \mathrm{~mA}(p=0.589$ for WT vs $\mathrm{BAD} \mathrm{KO}, p=0.011$ for WT vs BAX KO, $p=0.013$ for WT vs caspase-3 KO); $n=20-30$ cells from 5 mice for each group; Fig. $1 C]$. 
A

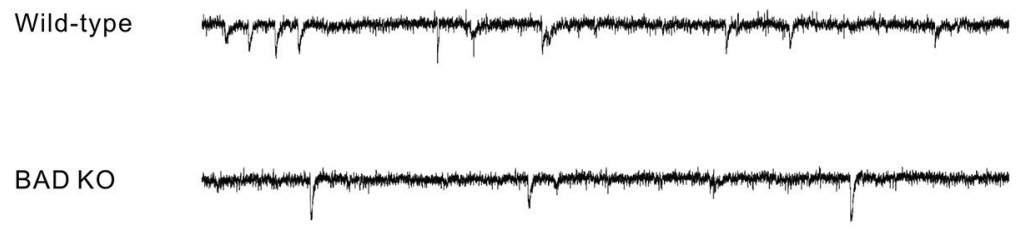

BAXKO
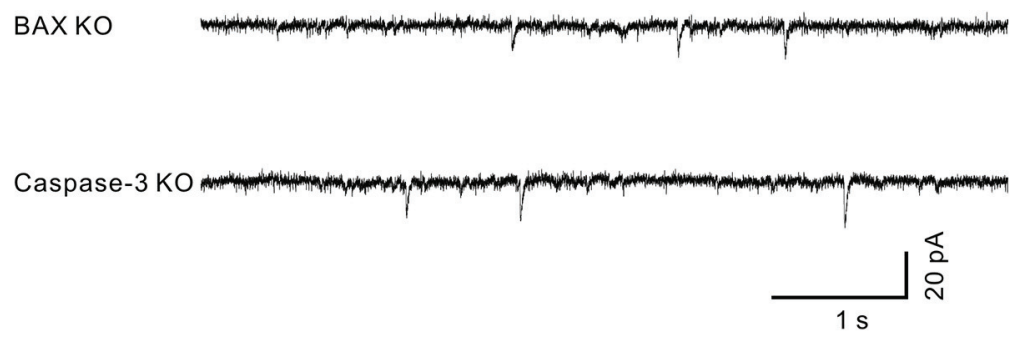
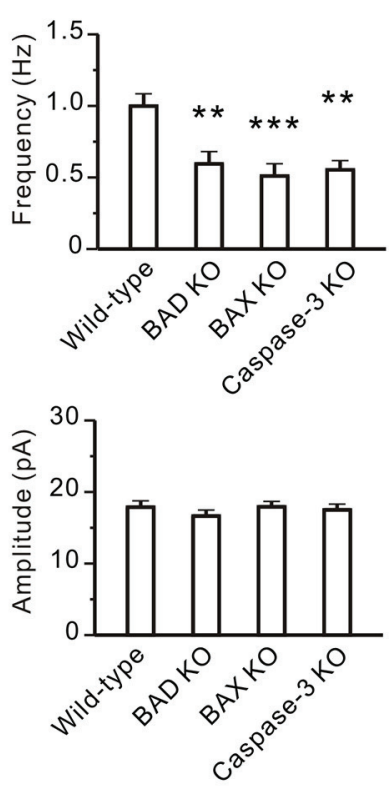

B
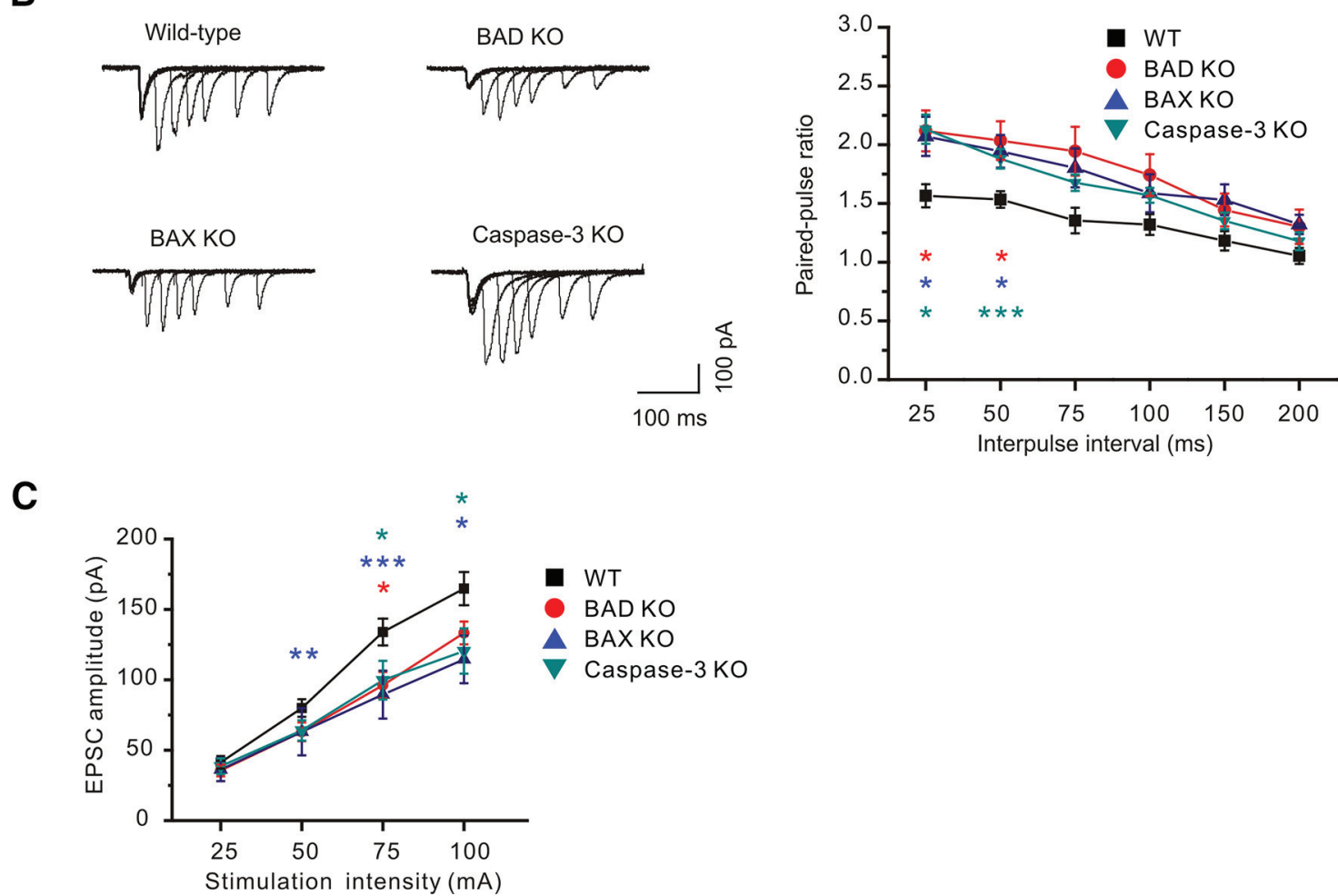

Figure 1. Presynaptic release is diminished in BAD, BAX, and caspase-3 K0 mice. Hippocampal slices were prepared from BAD, BAX, caspase-3 KO, and WT mice (P16-P19). CA1 pyramidal neurons were recorded at the holding potential of $-70 \mathrm{mV}$ in the whole-cell voltage-clamp configuration. $A$, Representative traces and measurement of mEPSCS recorded during a 10 min period in the presence of TTX $(1 \mu \mathrm{M})$. $\boldsymbol{B}$, Current traces evoked by paired-pulse stimulation and analysis of PPR. C, EPSCs evoked by current injection. Histograms represent mean \pm SEM. $n=20$ 30 neurons from 5 mice for each group. $* p<0.05 ; * * p<0.01 ; * * * p<0.001$; comparison between WT and K0 animals.

Together, these findings indicate that presynaptic function is altered in $\mathrm{BAD}, \mathrm{BAX}$, and caspase- $3 \mathrm{KO}$ mice.

\section{Synaptic vesicle number is reduced in BAD, BAX, and} caspase-3 KO mice

Presynaptic release probability is proportional to the pool size of readily releasable synaptic vesicles (Dobrunz and Stevens, 1997). To assess the size of RRPs, we used rapid electrical stimulation or hypertonic solution to deplete RRP. For electrical stimulation, 40 minimal stimuli at $10 \mathrm{~Hz}$ were delivered to $\mathrm{CA} 1$ neurons to elicit quantal release and deplete RRP, and the total number of evoked quanta release was counted as previously reported (Dobrunz and Stevens, 1997). Compared with WT mice, BAD, BAX, and caspase-3 KO mice decreased RRP (one-way ANOVA was used for comparison across groups, $F_{(3,38)}=4.148, p=0.012$; StudentNewman-Keuls method was used for post hoc analysis; WT: $4.98 \pm 0.207$; BAD KO: $4.16 \pm 0.194, p=0.010$ for KO vs WT; BAX KO: $4.02 \pm 0.229, p=0.015$ for KO vs WT; caspase- $3 \mathrm{KO}$ : $4.15 \pm 0.216, p=0.028$ for KO vs WT; $n=10$ or 11 cells from 3 mice for each group; Fig. $2 A$ ). 
A
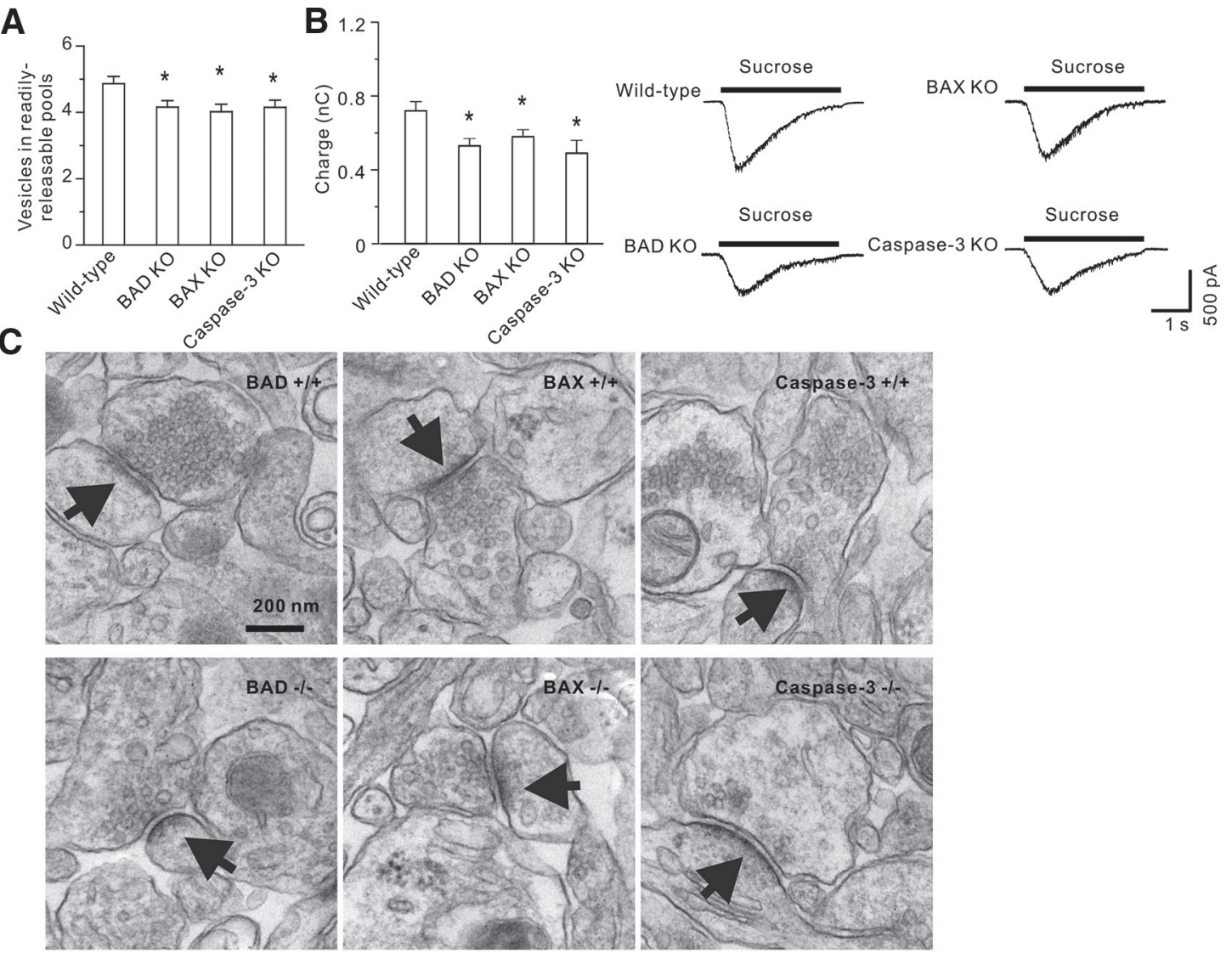

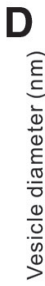
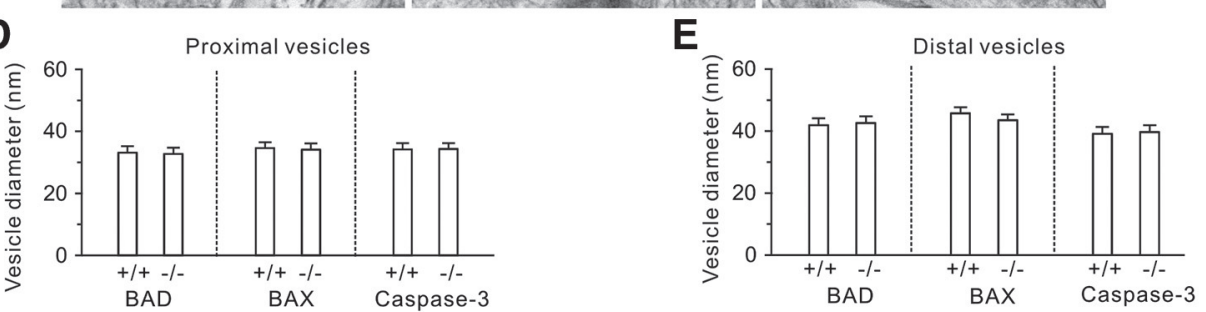

$\mathbf{F}$

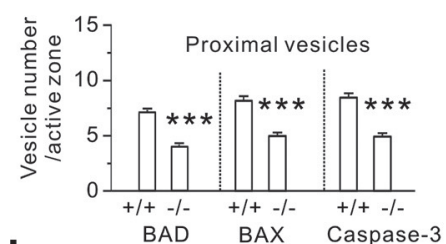

I

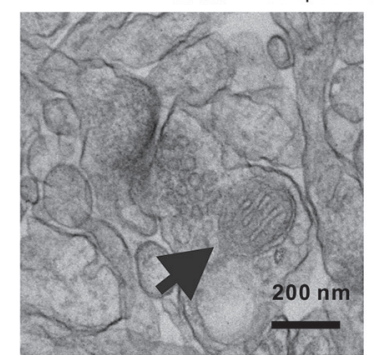

G

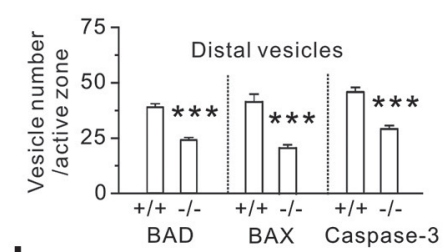

$\mathbf{J}$

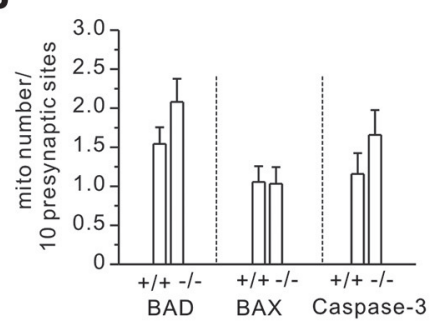

$\mathbf{H}$
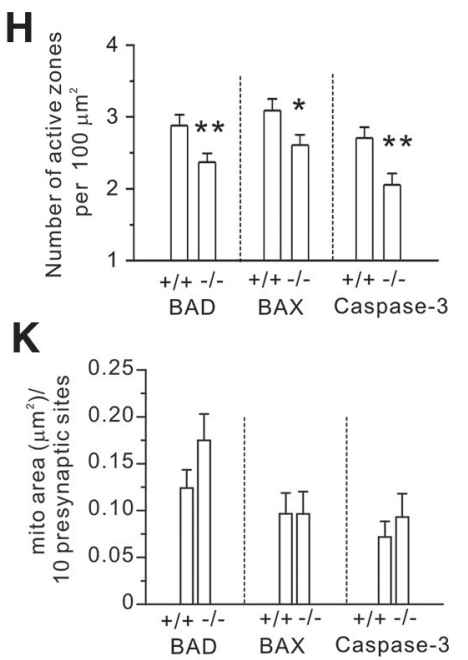

Figure 2. Synaptic vesicle pools are reduced in BAD, BAX, and caspase-3 K0 mice. Hippocampal slices were prepared from BAD, BAX, caspase-3 KO, and WT mice (P16-P19) for whole-cell recordings $(\boldsymbol{A}, \boldsymbol{B})$ or electron microscopy $(\boldsymbol{C}-\boldsymbol{K})$. $\boldsymbol{A}$, RRP assessed from quantal release evoked by 40 minimal stimuli at $10 \mathrm{~Hz}$ delivered to CA1 neurons. $\boldsymbol{B}$, Representative traces of EPSCS evoked by local application of hypertonic solution ( $500 \mathrm{~mm}$ sucrose, $3 \mathrm{~s}$ ), and quantification of total charge transfer between the onset of EPSCs and the time point at which EPSCs decays to $10 \%$ of the peak amplitude. CA1 neurons were recorded at $-70 \mathrm{mV}$ in the whole-cell voltage-clamp mode. $n=8$ or 9 neurons from 3 mice for each group. One-way ANOVA was used to compare across groups; $F_{(3,31)}=4.233, p=0.013$. Student-Newman-Keuls method was used for post hoc analysis. $C$, $I$, Representative electron micrographs taken from randomly selected CA1 regions containing synapses. Arrows indicate synapses in $\mathbf{C}$ and mitochondria in $\boldsymbol{I}$. $\boldsymbol{D}-\mathbf{G}$, The average diameter and the number of proximal vesicles and distal vesicles. $\boldsymbol{H}$, The density of active zones. $\boldsymbol{J}$, The number of mitochondria at the presynaptic site. $\boldsymbol{K}$, The area of mitochondria at the presynaptic site. Mann-Whitney $\boldsymbol{U}$ test was used for statistical analysis in $\boldsymbol{D}-\boldsymbol{H}, \boldsymbol{J}, \boldsymbol{K} . \mathbf{n}=100-150$ images from 3 mice for each group. Data are mean \pm SEM. $* p<0.05 . * * p<0.01 . * * * p<0.001$. 
To assess RRP with hypertonic solutions as reported (Rosenmund and Stevens, 1996), acute hippocampal slices prepared from WT and KO mice (16-19 d old) were stimulated with ACSF containing $500 \mathrm{~mm}$ sucrose for 3 s. Sucrose-evoked responses were reduced in KO cells (one-way ANOVA was used for comparison across groups, $F_{(3,31)}=4.233$, $p=0.013$; StudentNewman-Keuls method was used for post hoc analysis; WT: $0.72 \pm 0.047 \mathrm{nC}$; BAD KO: $0.53 \pm 0.041 \mathrm{nC}, p=0.025$ for $\mathrm{KO}$ vs WT; BAX KO: $0.56 \pm 0.038 \mathrm{nC}, p=0.034$ for $\mathrm{KO}$ vs WT; caspase- $3 \mathrm{KO}: 0.49 \pm 0.068 \mathrm{nC}, p=0.012$ for $\mathrm{KO}$ vs WT; $n=8$ or 9 cells from 3 mice for each group; Fig. $2 B$ ), suggesting that $\mathrm{KO}$ mice have smaller RRPs.

To directly assess the pool size of synaptic vesicles, we examined the hippocampal CA1 region of mice at 16-19 d of age using electron microscopy. Since synaptic vesicles in hippocampal neurons range from 30 to $50 \mathrm{~nm}$ in diameter (Harris and Sultan, 1995; Schikorski and Stevens, 1997; Hu et al., 2008), we included vesicles located within $60 \mathrm{~nm}$ of the active zone as proximal vesicles, which are putative docked vesicles. Vesicles further away from the active zone were classified as distal vesicles which are putative recycling and reserve pools. While the diameter of synaptic vesicles was comparable in $\mathrm{KO}$ and WT mice (Fig. $2 \mathrm{C}-$ $E), \mathrm{KO}$ mice had fewer proximal and distal vesicles per active zone (Fig. 2C,F,G). Docked vesicles and readily releasable vesicles are similar in number (Rizzoli and Betz, 2005). Fewer proximal vesicles in KO mice suggest that the RRP size is reduced and is consistent with our electrophysiological results. The number of active zones was also lower in the CAl neurons of BAD, BAX, and caspase- $3 \mathrm{KO}$ mice (Fig. $2 \mathrm{H}$ ), indicative of a decrease in synapse number, which can contribute to the reduction of mEPSC frequency. The mitochondrial number and content at the presynaptic site were comparable in WT and KO mice (Fig. 2I-K).

Together, these findings indicate that $\mathrm{BAD}, \mathrm{BAX}$, and caspase-3 KO mice have fewer synaptic vesicles.

\section{Autophagy is increased in $\mathrm{BAD}, \mathrm{BAX}$, and caspase- $3 \mathrm{KO}$ neurons}

In the electron micrographs of caspase- $3 \mathrm{KO}$ mice, we noticed more autophagosome-like structures than in WT mice (Fig. $3 A$, $B)$, suggesting that autophagy is elevated. To confirm this, we analyzed autophagic flux by immunoblotting against microtubuleassociated protein LC3 and p62. LC3 is an autophagy-related (Atg) protein cleaved by the cysteine protease Atg4 and conjugated to phosphatidylethanolamine during autophagy (Ichimura et al., 2000; Kabeya et al., 2004). Lipidated LC3 (LC3-II) remains on mature autophagosomes and therefore is often used in combination with p62 (a protein selectively degraded by autophagy) to indicate autophagic flux (Kabeya et al., 2000; Mizushima et al., 2004, 2010; Bjorkoy et al., 2005; Shibutani and Yoshimori, 2014).

In the hippocampus of caspase-3 KO mice, LC3-II increased, while p62 decreased (Fig. 3C,D), indicating that autophagic flux is enhanced. Additionally, Atg3, $-4 \mathrm{~B},-7,-9$, and Beclin-1(Atg6) also increased in caspase- $3 \mathrm{KO}$ mice (Fig. $3 C, D$ ), suggesting that autophagy overactivation may arise from Atg protein increase. Since caspase-3 cleaves Atg3, -4B, -6, -7, and -9 (Norman et al., 2010), autophagy elevation in caspase-3 KO mice may result from attenuated caspase- 3 activity. To test for the effect of reducing caspase- 3 activity on autophagy, we treated WT hippocampal slices with the caspase- 3 inhibitor DEVD-fmk (10 $\mu \mathrm{M})$. DEVDfmk increased LC3-II, Atg3, -4B, -5, -7, -9, and decreased p62 (Fig. 3E,F). To test whether the effect of DEVD-fmk is specific, we treated hippocampal slices with other protease inhibitors, including the calpain (a cysteine protease) inhibitor carbobenzoxy-valinyl-phenylalaninal $(10 \mu \mathrm{M})$, serine protease inhibitor aprotinin $(10 \mu \mathrm{g} / \mathrm{ml})$, or aspartyl protease inhibitor pepstatin A $(10 \mu \mathrm{g} / \mathrm{ml})$. These inhibitors had no effect on the Atg proteins, LC3-II or p62 (Fig. 3G-I). These results indicate that a reduction of caspase- 3 activity can enhance autophagic flux in the hippocampus.

Since BAD and BAX are components of the mitochondrial pathway for caspase- 3 activation, we tested whether caspase- 3 activity and autophagy are altered in BAD and BAX KO mice. To our surprise, the levels of cleaved caspase-3 (the active form of caspase-3), LC3-II, p62, and Atg3, -4B, -6, -7, -9 were all comparable in the hippocampal lysates of $\mathrm{WT}, \mathrm{BAD}$, and $\mathrm{BAX} \mathrm{KO}$ mice (Fig. 4A,B). The hippocampal lysate was produced from tissues comprised of both glial cells and neurons. Glial cells express two pore-forming Bcl-2 family proteins BAX and BAK, both of which can mediate caspase-3 activation through the mitochondrial pathway. Caspase- 3 activity in the hippocampal lysate from $\mathrm{BAX}$ and $\mathrm{BAD} \mathrm{KO}$ mice, therefore, may not exhibit detectable changes since caspase- 3 can still be activated through BAK in glial cells. In contrast to glial cells, hippocampal neurons express only BAX (which is mainly activated by BAD in neurons), but not BAK (Sun et al., 2001; Uo et al., 2005; Jiao and Li, 2011). Hence, caspase- 3 activity in the hippocampal neurons of BAD and BAX KO mice may be reduced.

To analyze caspase-3 activity specifically in glial cells and neurons, we separately cultured hippocampal neurons and glial cells from $\mathrm{BAD}$ and $\mathrm{BAX} \mathrm{KO}$ mice. In the neural lysate of $\mathrm{BAD}$ and BAX KO mice, active caspase-3 and p62 decreased, while Atg3, $-4 \mathrm{~B},-6,-7,-9$, LC3-II increased (Fig. 4C,D). These proteins, however, were intact in glial cells prepared from BAD and BAX KO mice (Fig. 4E,F). Hence, $\mathrm{KO}$ of $\mathrm{BAD}$ and BAX increases autophagic flux in hippocampal neurons, but not in glial cells.

Together, these findings indicate that autophagy is increased in $\mathrm{BAD}, \mathrm{BAX}$, and caspase-3 KO neurons.

\section{The BAD-BAX-caspase-3 cascade controls synaptic vesicle number by regulating autophagy}

Having found that autophagy is increased in $\mathrm{BAD}, \mathrm{BAX}$, and caspase- $3 \mathrm{KO}$ mice, we tested whether this increase contributes to the decrease in synaptic vesicle number. We first examined whether autophagy influences synaptic vesicle pools in WT hippocampal slices (16-19d of age). Slices were treated with the mTOR inhibitor rapamycin $(10 \mu \mathrm{M}, 15 \mathrm{~min})$ to activate autophagy or CQ (120 $\mu \mathrm{M}, 2 \mathrm{~h})$, which inhibits autophagy by preventing autophagosome acidification and the fusion of autophagosomes with lysosomes (Boya et al., 2005; Shacka et al., 2006). Interestingly, rapamycin decreased RRPs larger than the average size before treatment (referred to as large pools) and had no effect on the rest of RRPs (referred to as small pools), whereas CQ increased smaller RRPs without affecting larger RRPs (Fig. $5 A-C)$. These results indicate that autophagy limits the size of synaptic vesicle pools. The pool size-dependent effects of rapamycin and CQ suggest that autophagy can modulate synaptic vesicle pools only when they are within the range of the maximal and minimal sizes. Consistent with the effect of rapamycin and CQ on RRP, rapamycin increased, while CQ decreased, PPR (Fig. 5D,E). Hence, autophagy restricts the number of synaptic vesicles and presynaptic release probability. Unlike in WT slices, rapamycin had no effect on PPR or RRP in BAD, BAX, and caspase-3 KO slices (Fig. $5 F-I$ ), presumably because neurons in the KO slices already had elevated autophagy and smaller RRP, which could not be further reduced by rapamycin. Our findings that RRP can be altered by CQ and rapamycin within $2 \mathrm{~h}$ are 
A

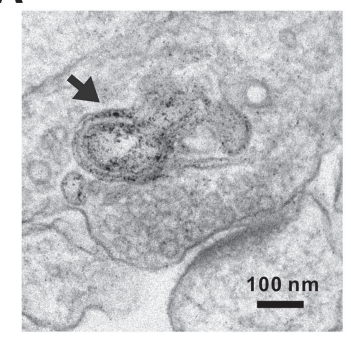

E

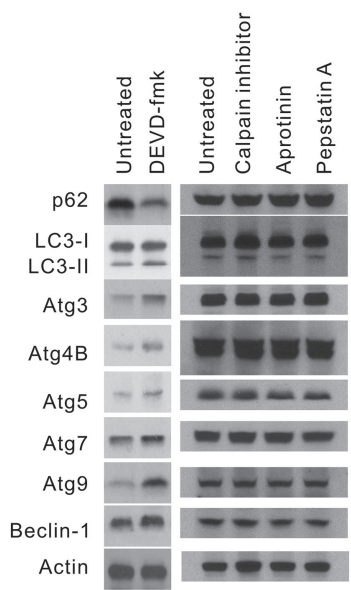

B

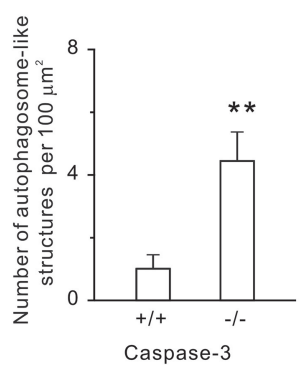

F

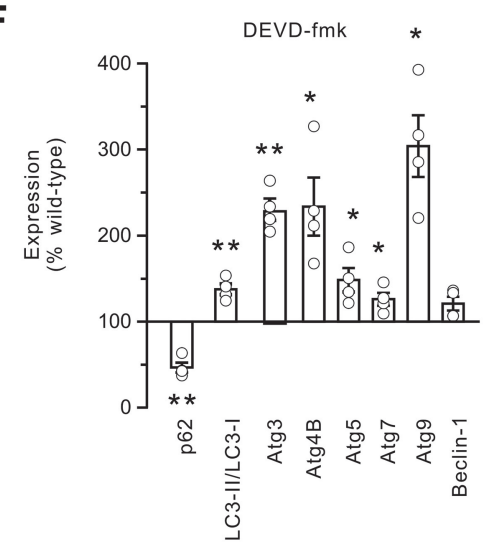

H

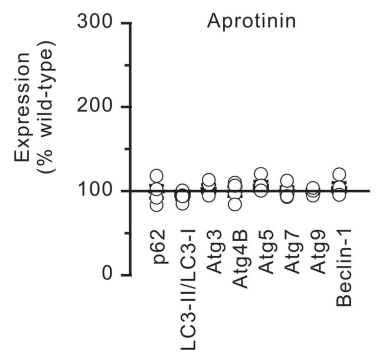

C

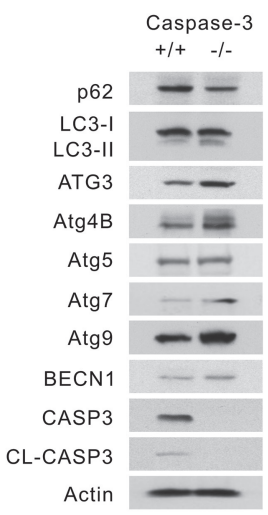

\section{I}

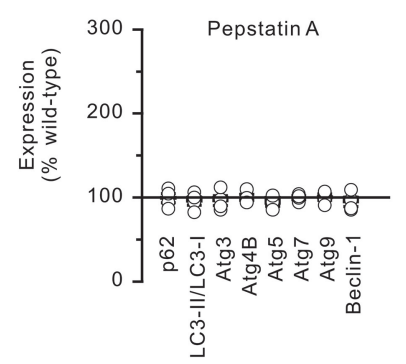

D

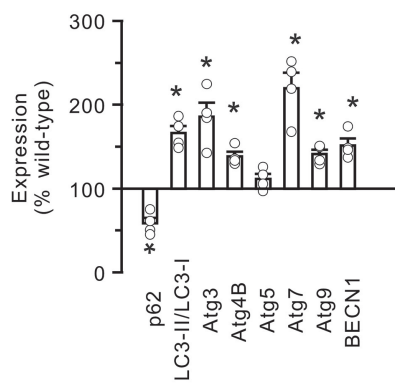

G

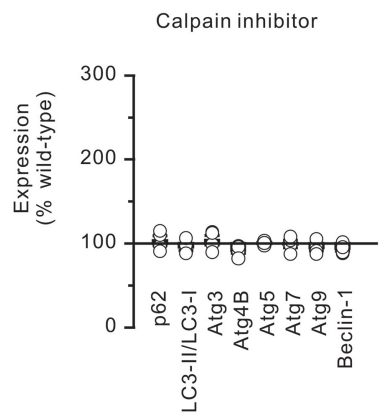

Figure 3. Autophagosome-like structures and Atg protein expression in caspase-3 K0 mice. Hippocampal slices were prepared from caspase-3 K0 mice (P16-P19) for electron microscopy in $\boldsymbol{A}, \boldsymbol{B}$. A, Representative electron micrograph for caspase-3 KO hippocampal slices. Arrow indicates an autophagosome-like structure at the presynaptic site. $\boldsymbol{B}$, The density of autophagosomelike structures in the electron micrographs taken from randomly selected CA1 regions containing synapses. $n=100$ images from 3 mice for each group. Two-tailed Student's $t$ test was used for statistical analysis. C, D, Hippocampal tissue lysates prepared from caspase-3 KO mice (P16-P19) were used for immunoblotting. C, Representative Western blots of hippocampal tissue lysates. D, Quantification of $\boldsymbol{C}$. $\boldsymbol{E}$-I, Hippocampal slices from WT mice were treated with designated inhibitors (DEVD-fmk for caspase-3, carbobenzoxy-valinyl-phenylalaninal for calpain, pepstatin A for aspartyl proteases, and aprotinin for serine proteases). $\boldsymbol{E}$, Representative immunoblots of hippocampal slices treated with protease inhibitors. $\boldsymbol{F}$-I, Quantification of $\boldsymbol{E}$; $n=4$ experiments for each condition. Mann-Whitney $U$ test was used for comparison. $\boldsymbol{B}$, Data are mean \pm SEM. $\boldsymbol{D}, \boldsymbol{F}-\mathbf{I}$, Values of individual experiments and mean \pm SEM. $* p<0.05$. $* * p<0.01$.

consistent with earlier reports that RRP can be rapidly remodeled, such as during Hebbian plasticity (Goda and Stevens, 1998; Rey et al., 2020).

We next tested whether increased autophagy is responsible for fewer synaptic vesicles in $\mathrm{BAD}, \mathrm{BAX}$, and caspase-3 KO neurons. Hippocampal slices from WT, BAD, BAX, and caspase-3 KO mice (16-19d of age) were treated with CQ $(120 \mu \mathrm{M}, 2 \mathrm{~h})$. CQ decreased PPR and increased RRP in KO slices (Fig. 5J,K). Hence, the reduction of synaptic vesicle numbers in $\mathrm{BAD}, \mathrm{BAX}$, and caspase- $3 \mathrm{KO}$ mice is attributable to elevated autophagic activity.

Together, these findings indicate that the BAD-BAX-caspase3 cascade controls the size of synaptic vesicle pools through autophagy.

\section{Autophagy in presynaptic neurons is required to maintain} the size of synaptic vesicle pools

The increase in synaptic vesicle number by CQ suggests that basal autophagic activity controls the size of synaptic vesicle pools. To validate this finding with molecular genetic approaches, we generated constructs expressing siRNAs against Atg5 and Beclin-1, two components of the autophagy pathway. The efficacy and specificity of these siRNAs against exogenously and endogenously expressed targets were tested in HEK293 cells and primary hippocampal neurons (Fig. $6 A-D$ ). Expression of these siRNAs in hippocampal neurons caused a decrease in LC3-II and an increase in p62 (Fig. 6E), indicating that they inhibit autophagy. 
A

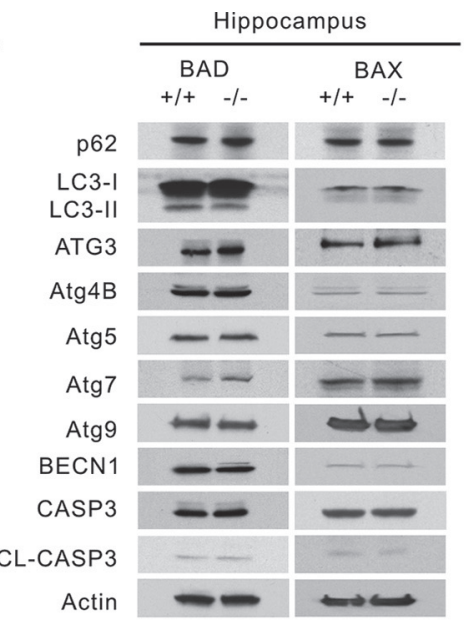

C

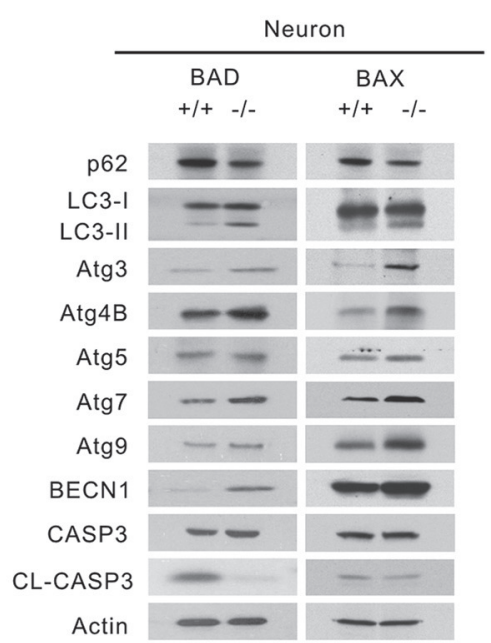

$\mathbf{E}$

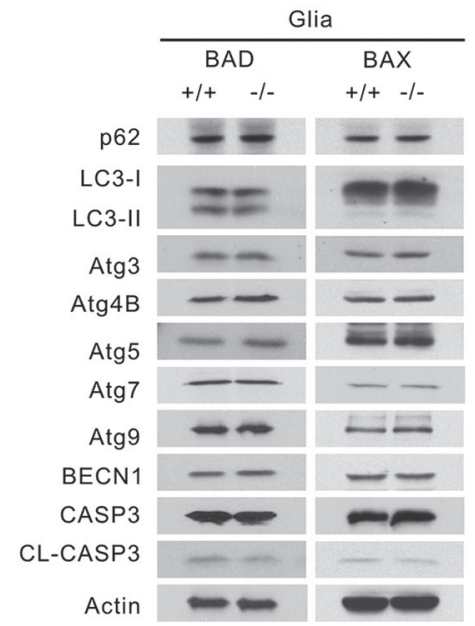

B

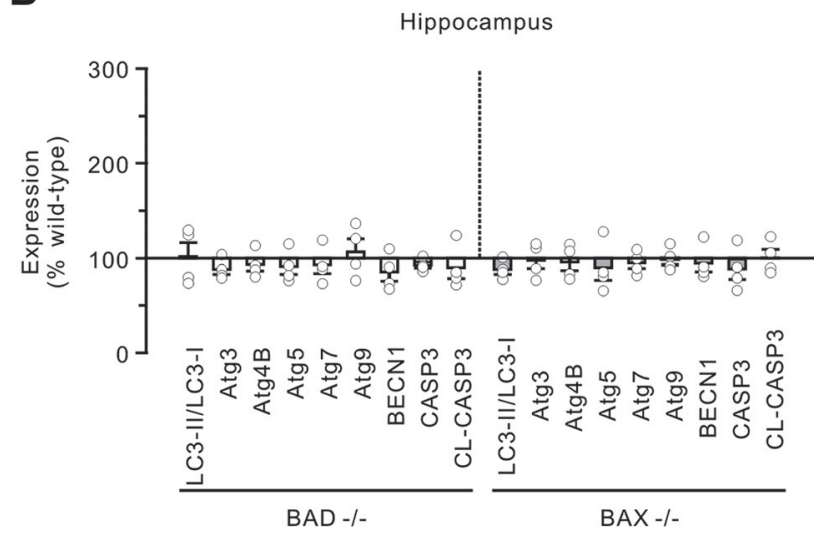

D

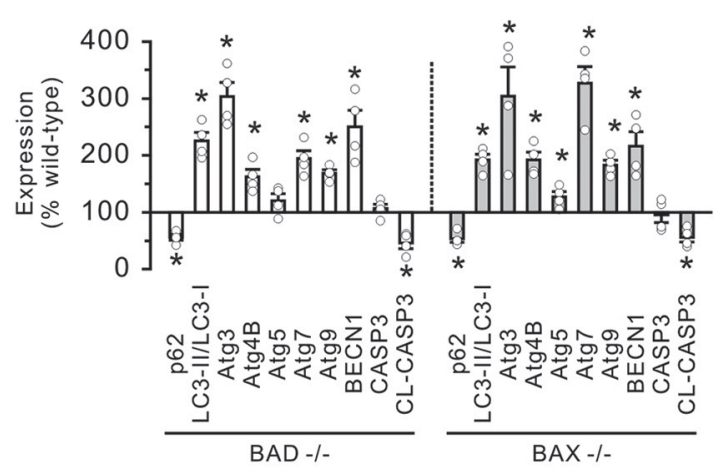

$\mathbf{F}$

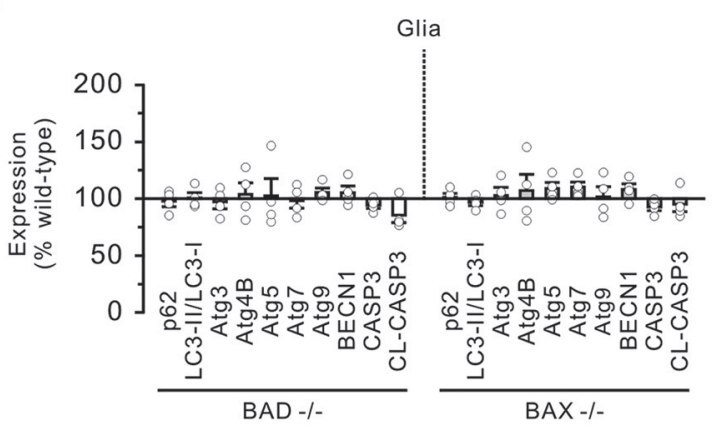

Figure 4. The expression of Atg proteins in hippocampal tissue lysates, primary neurons, and glial cells of BAD, BAX KO mice. $A$, Representative Western blots of hippocampal tissue lysates. $\boldsymbol{B}$, Quantification of $\boldsymbol{A}$. C, Representative Western blots of cell lysates from primary neurons. D, Quantification of $\boldsymbol{C}$. $\boldsymbol{E}$, Representative Western blots of cell lysates from glial cells. $\boldsymbol{F}$, Quantification of $\boldsymbol{E} . n=4$ experiments for each condition. The data are plotted as values of individual experiments and mean \pm SEM. Mann-Whitney $U$ test was used for comparison between WT and K0 samples. $* p<0.05$.

The Atg5 and Beclin-1 siRNAs were biolistically transfected into cultured hippocampal slices. PPR and RRP were assessed using double whole-cell recordings of transfected and untransfected pairs of CA1 neurons. We noticed that the size of synaptic vesicle pools in cultured hippocampal slices was similar to that of small pools in acute hippocampal slices. We therefore did not separate synaptic vesicle pools into large and small pools for RRP analysis here. When the Atg5 siRNA and the Beclin-1 siRNA were expressed in presynaptic neurons, PPR decreased and RRP increased (Fig. 6F). These effects were abrogated by 
A

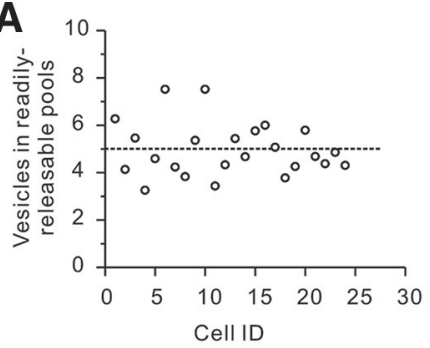

D

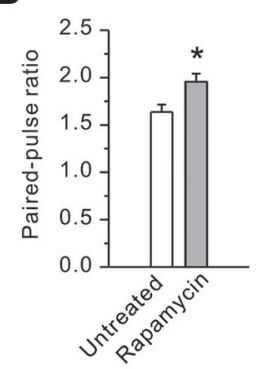

G

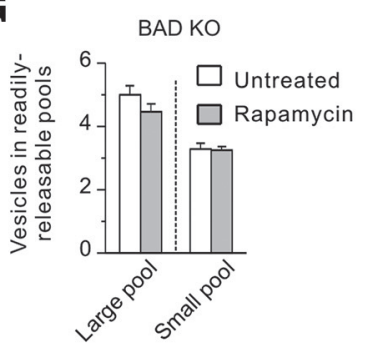

J

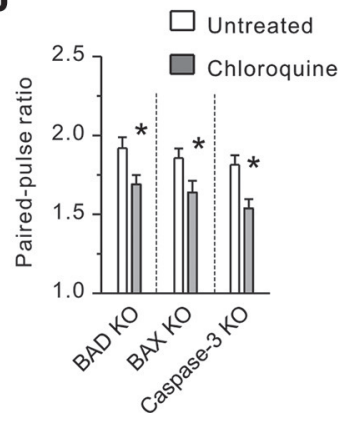

B

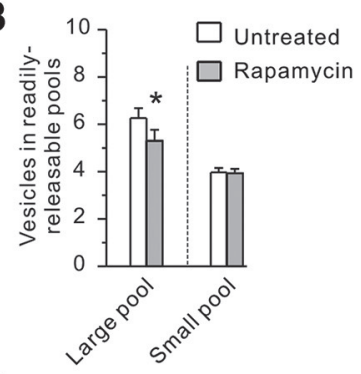

E

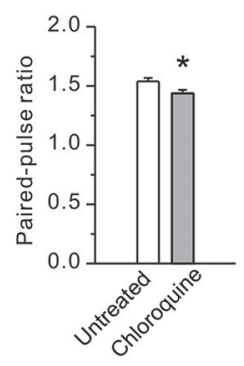

H

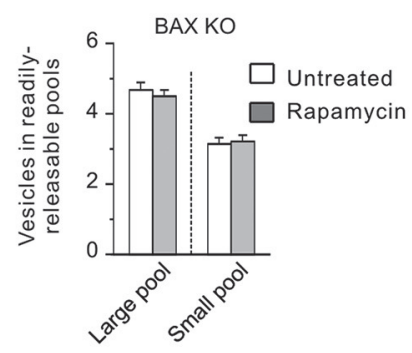

K

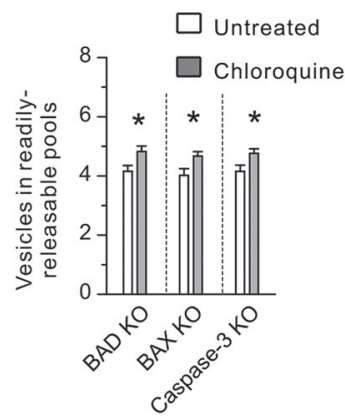

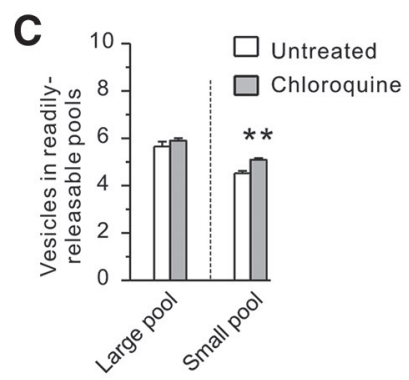

$\mathbf{F}$
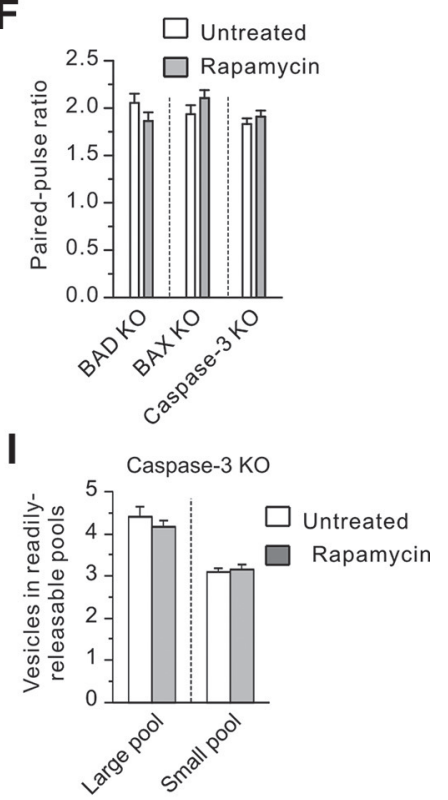

Figure 5. Autophagy negatively regulates the pool size of synaptic vesicles. CA1 neurons were recorded in acute hippocampal slices prepared from WT and K0 mice (P16-P19). Rapamycin $(10 \mu \mathrm{m})$ and $\mathrm{CQ}(120 \mu \mathrm{m})$ were added to the bath at $15 \mathrm{~min}$ and $2 \mathrm{~h}$, respectively, before recording and perfused throughout the experimental period. $\boldsymbol{A}$, The distribution of RRP size in WT mice. Line indicates average RRP size and divides RRP into large (above the line) and small pools (below the line). $\boldsymbol{B}$, The effect of rapamycin on synaptic vesicle pools. $\boldsymbol{C}$, The effect of CQ on synaptic vesicle pools. $\boldsymbol{D}$, The effect of rapamycin on PPR. $\boldsymbol{E}$, The effect of CQ on PPR. $\boldsymbol{F}-\boldsymbol{I}$, The changes in PPR and RRP in BAD, BAX, and caspase-3 KO mice after rapamycin treatment. $\boldsymbol{J}$, The changes in PPR in BAD, BAX, and caspase-3 KO mice were attenuated by $C Q$ treatment. $K$, RRPs in BAD, BAX, and caspase- 3 KO mice were restored by $C Q$ treatment. $n=10-12$ neurons from 2 or 3 animals for each group. Data are mean \pm SEM. Mann-Whitney $U$ test was used for computing $p$ values. $* p<0.05$. $* * p<0.01$.

cotransfection of a construct expressing their corresponding targets with silent mutations in the siRNA binding site that made them siRNA-resistant (Fig. $6 A, B, F$ ). By contrast, when the Atg5 siRNA and Beclin-1 siRNA were expressed in postsynaptic neurons, they had no effect on PPR or RRP (Fig. 6F). Thus, presynaptic, but not postsynaptic, autophagic activity is required to maintain the size of synaptic vesicle pools. Likewise, knockdown of Atg 5 or Beclin-1 by siRNAs in presynaptic hippocampal neurons of $\mathrm{BAD}, \mathrm{BAX}$, or caspase-3 $\mathrm{KO}$ mice decreased PPR and increased RRP (Fig. 6G,H). These results indicate that it is autophagy in presynaptic neurons that mediates the change to synaptic vesicle pools in $\mathrm{BAD}, \mathrm{BAX}$, and caspase-3 $\mathrm{KO}$ mice.
To confirm the regulation of synaptic vesicles by autophagy in vivo, we generated conditional Atg5 and Atg7 KO mice with presynaptically or postsynaptically specific deficiency of these proteins in the Schaffer collateral pathway. To this end, we crossed the floxed Atg5 and the floxed Atg7 mice with transgenic mice expressing Cre recombinase selectively in the CA1 (for postsynaptic KO) or CA3 (for presynaptic KO) region (Tsien et al., 1996; Nakazawa et al., 2002). In these mice, Atg protein expression and autophagy decreased, and rapamycin-induced activation of autophagy was blocked (Fig. $7 A, B$ ). The residual Atg protein in the conditional $\mathrm{KO}$ mice is likely because of the late onset of Cre recombinase expression (Tsien et al., 1996; Nakazawa et al., 2002). 
A

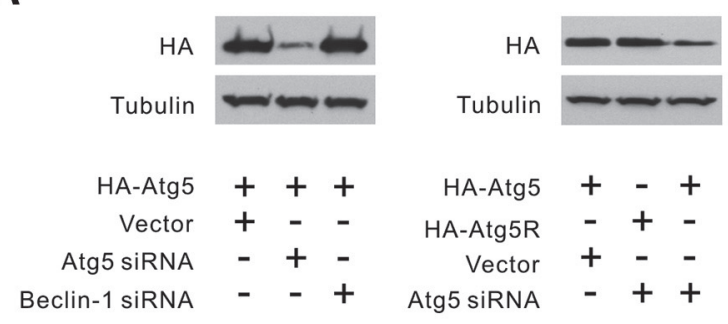

B

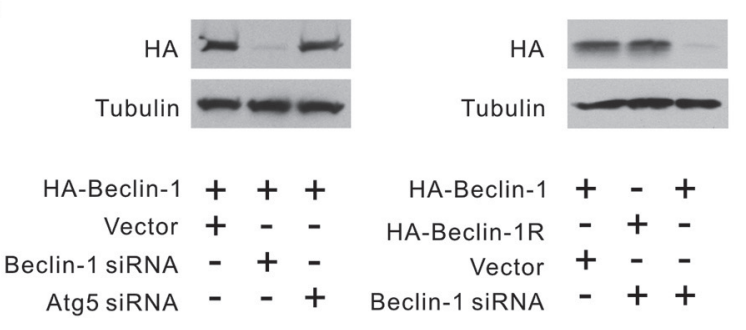

C

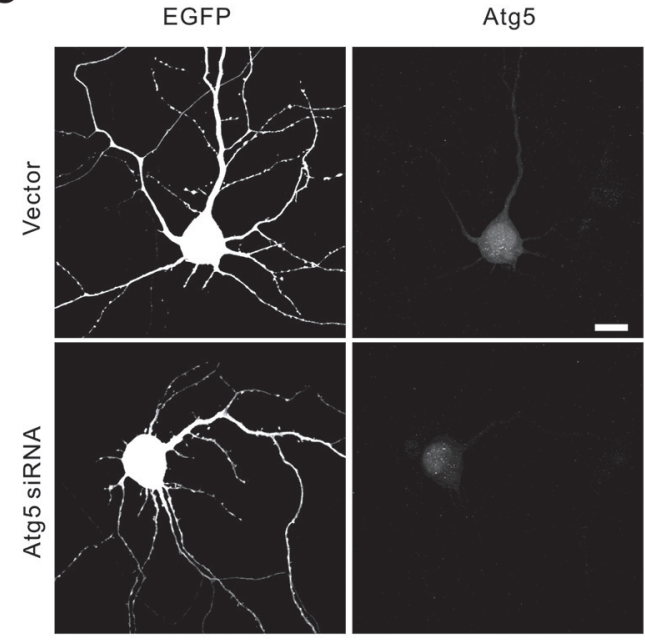

F

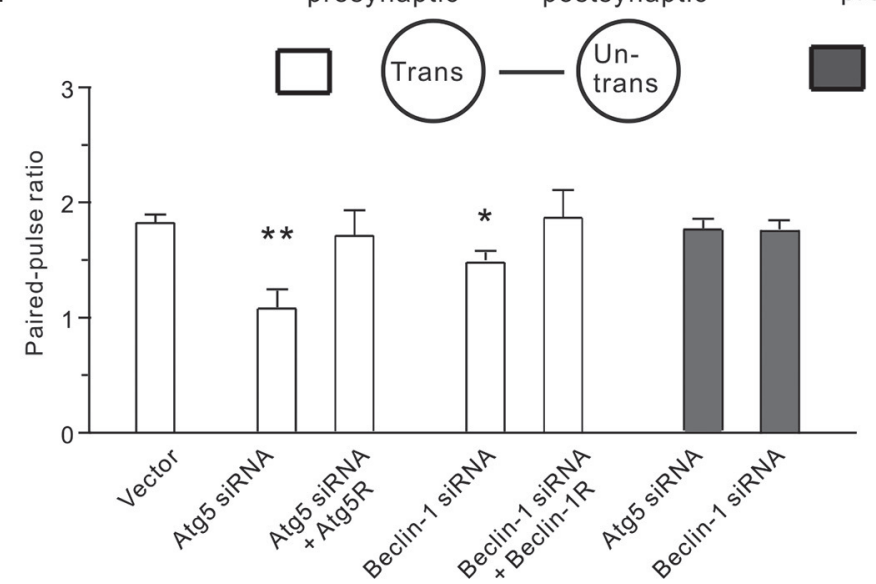

G

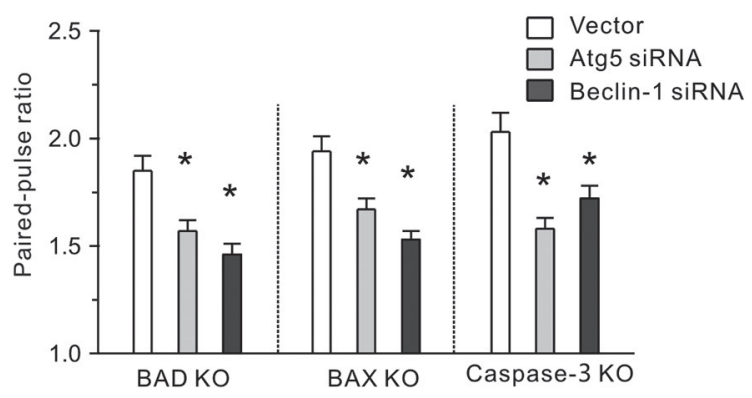

D

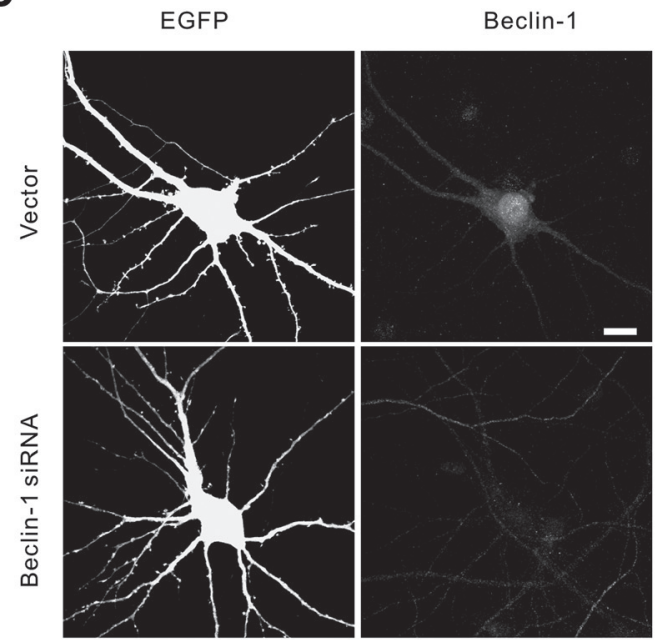

E

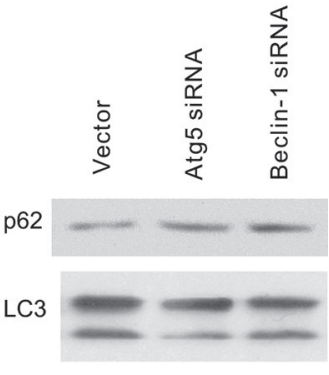

presynaptic postsynaptic
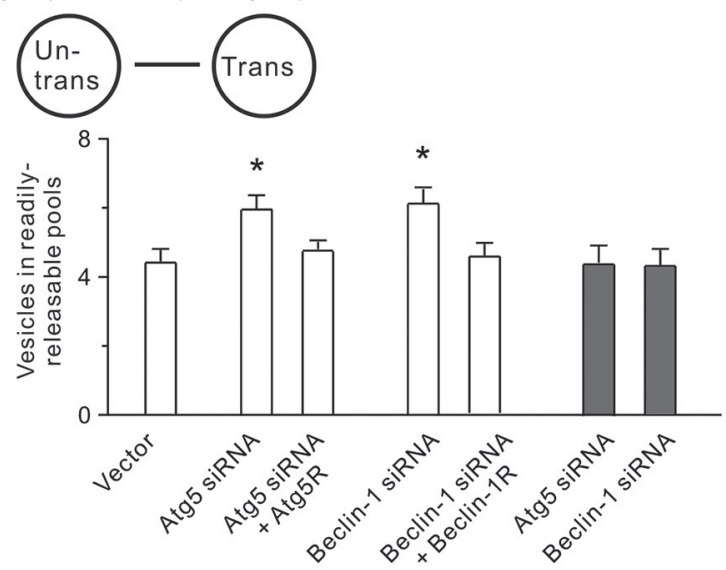

H

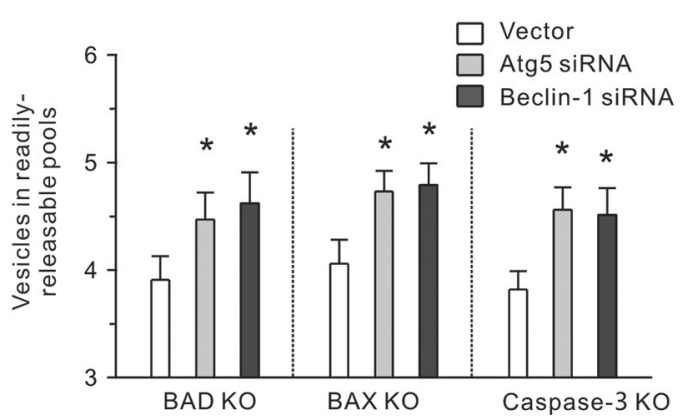

Figure 6. Autophagy in presynaptic neurons is required to maintain the size of synaptic vesicle pools. $\boldsymbol{A}, \boldsymbol{B}$, The efficacy and specificity of siRNAs against Atg5 and Beclin-1. HEK293 cells were transfected with constructs expressing siRNAs against Atg5 and Beclin-1 along with plasmids expressing HA-tagged Atg5, Beclin-1, or their siRNA-resistant mutants (Atg5R and BECN1R). Cells were harvested for immunoblotting against HA at $2 \mathrm{~d}$ after transfection. C, D, Cultured hippocampal neurons (DIV14) were transfected with plasmids expressing siRNAs against Atg5 and Beclin-1, or empty vectors along with the EGFP construct, and stained for endogenous Atg5 and Beclin-1 at $3 \mathrm{~d}$ after transfection. $E$, Cultured hippocampal neurons were transduced with lentivirus expressing Atg5 or Beclin-1 siRNAs and lysed for immunoblotting at $6 \mathrm{~d}$ after transduction. $\boldsymbol{F}-\boldsymbol{H}$, CA1 neurons were recorded in cultured WT $(\boldsymbol{F})$ or KO $(\boldsymbol{G}, \boldsymbol{H})$ hippocampal slices biolistically transfected with constructs expressing siRNAs against Atg5 or Beclin-1 alone or along with constructs expressing their siRNA resistant target genes. Pairs of transfected and nearby untransfected 

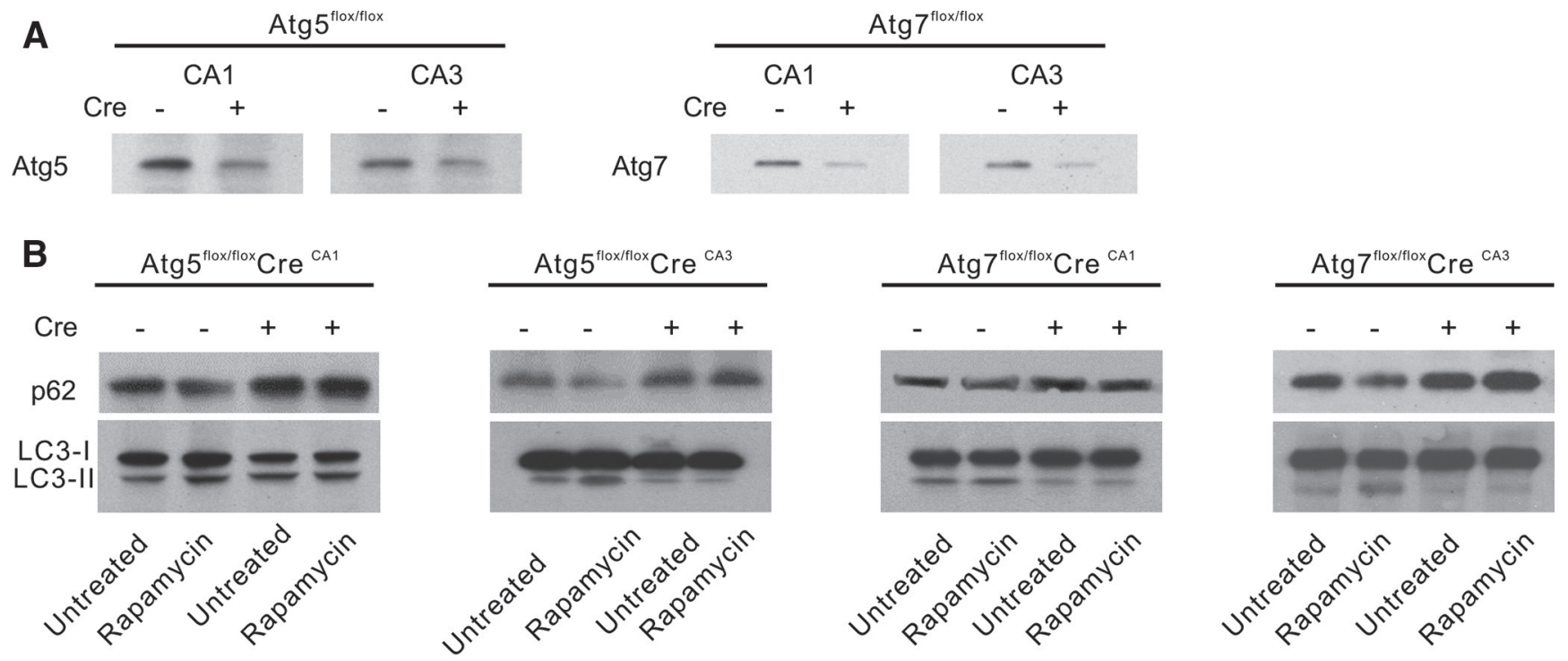

C
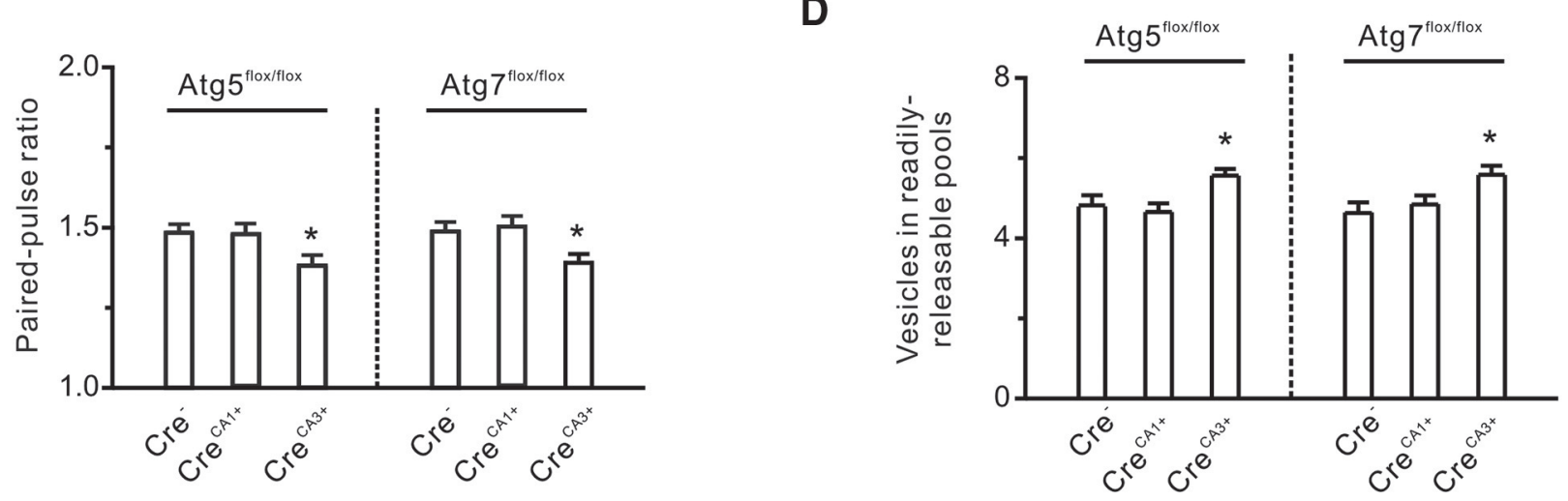

Figure 7. PPR and RRP in mice (P16-P19) with Atg5 or Atg7 K0 in presynaptic $\left(\mathrm{Cre}^{\mathrm{CA} 3+}\right)$ or postsynaptic (Cre $\left.{ }^{\mathrm{CA} 1+}\right)$ neurons. $\boldsymbol{A}, \boldsymbol{B}$, Atg proteins and autophagy are reduced in conditional Atg5 and Atg7 K0 mice. The CA1 (for the Cre ${ }^{\mathrm{CA} 1}$ line) or the CA3 (for the $\mathrm{Cre}^{\mathrm{CA} 3}$ line) region was removed from mice (P16-P19) for immunoblotting. $A$, Immunoblots with antibodies against Atg5 and Atg7. B, Hippocampal slices were treated with rapamycin $(10 \mu \mathrm{m}, 30 \mathrm{~min})$ and then lysed for immunoblotting. C, D, PPR and RRP in mice (P16-P19) with Atg5 or Atg7 K0 in presynaptic (Cre ${ }^{\mathrm{CA}+}$ ) or postsynaptic ( $\left(\mathrm{Cre}^{\mathrm{CA} 1+}\right)$ neurons of the Schaffer collateral pathway. $n=11$ or 12 neurons from 2 or 3 animals for each group. Data are mean \pm SEM. Mann-Whitney $U$ test was used for computing $p$ values. $* p<0.05$.

Hippocampal slices were prepared from $\mathrm{KO}\left(\mathrm{Cre}^{+}\right)$and WT $\left(\mathrm{Cre}^{-}\right)$littermates (16-19 d of age) and recorded in the CA1 region to test for PPR and RRP. In the CA3-specific Atg5 and Atg7 KO mice, PPR was reduced $\left[\operatorname{Atg} 5^{\text {flox/flox }} \mathrm{Cre}^{-}: 1.49 \pm 0.028\right.$; Atg $5^{\text {flox/flox }} \mathrm{Cre}^{\mathrm{CA3}+}: 1.38 \pm 0.031, p=0.03$ for $\mathrm{KO}$ vs $\mathrm{Cre}^{-}$; Atg $7^{\text {flox/llox }} \mathrm{Cre}^{-}: 1.49 \pm 0.032 ;$ Atg $^{\text {flox/flox }} \mathrm{Cre}^{\mathrm{CA} 3+}: 1.39 \pm$ $0.020, p=0.022$ for $\mathrm{KO}$ vs $\mathrm{Cre}^{-} ; n=10$ cells from 3 mice for each group; one-way ANOVA $\left(F_{(2,27)}=4.612, p=0.019\right.$ for Atg5, $F_{(2,27)}=4.765, p=0.017$ for Atg7) and post hoc StudentNewman-Keuls method were used for statistics analysis; Fig. $7 C$ ], while RRP was increased [Atg5 $5^{\text {flox/flox }} \mathrm{Cre}^{-}: 4.77 \pm 0.27$; Atg $5{ }^{\text {flox/flox }} \mathrm{Cre}^{\mathrm{CA} 3+}$ : $5.58 \pm 0.22, p=0.033$ for $\mathrm{KO}$ vs $\mathrm{Cre}^{-}$;

\section{$\leftarrow$}

CA1 neurons were recorded simultaneously in the whole-cell recording mode at $2 \mathrm{~d}$ after transfection in $\boldsymbol{F}-\boldsymbol{H}$. $\boldsymbol{F}$, Effects of Atg5 and Beclin-1 knockdown on PPR and RRP. Data of presynaptically and postsynaptically transfected cells are shown as empty and solid bars, respectively; $n=8$ or 9 pairs of neurons from 2 or 3 animals for each group. $\mathbf{G}, \boldsymbol{H}$, CA1 neurons in BAD, BAX, or caspase-3 K0 mice were transfected with Atg5 siRNAs or Beclin-1 siRNAs and recorded for analysis of PPR and RRP; $n=10$ neurons from 2 animals for each group. Oneway ANOVA and post hoc Student-Newman-Keuls method were used for statistical analysis. Data are mean \pm SEM. Statistical significance between vector and other groups: $* p<0.05$; $* * p<0.01$. Scale bars: $\boldsymbol{C}, \boldsymbol{D}, 20 \mu \mathrm{m}$.
Atg $7^{\text {flox/flox }} \mathrm{Cre}^{-}: 4.62 \pm 0.28 ; A \operatorname{Atg} 7^{\text {flox/flox }} \mathrm{Cre}^{\mathrm{CA} 3+}: 5.59 \pm 0.23$, $p=0.028$ for $\mathrm{KO}$ vs $\mathrm{Cre}^{-} ; n=11$ cells from 3 mice for each group; one-way ANOVA $\left(F_{(2,30)}=3.682, p=0.037\right.$ for Atg5, $F_{(2,30)}=4.085, p=0.027$ for Atg7) and post hoc StudentNewman-Keuls method were used for statistics analysis; Fig. $7 D]$. In CA1-specific Atg5 and Atg7 KO mice, by contrast, both PPR (Atg $5{ }^{\text {flox/flox }} \mathrm{Cre}^{\mathrm{CA}{ }^{+}+}: 1.48 \pm 0.025, p=0.861$ for $\mathrm{KO}$ vs $\mathrm{Cre}^{-}$; Atg $7^{\text {flox/flox }} \mathrm{Cre}^{\mathrm{CA1}+}: 1.51 \pm 0.034, p=0.667$ for $\mathrm{KO}$ vs $\mathrm{Cre}^{-} ; n=10$ cells from 3 mice for each group; Fig. $7 C$ ) and RRP $\left(\mathrm{Atg} 5^{\text {flox/flox }} \mathrm{Cre}^{\mathrm{CA} 1+}\right.$ : $4.70 \pm 0.27, p=0.837$ for $\mathrm{KO}$ vs $\mathrm{Cre}^{-}$; Atg $7^{\text {flox/flox }} \mathrm{Cre}^{\mathrm{CA} 1+}: 4.84 \pm 0.25, p=0.541$ for $\mathrm{KO}$ vs $\mathrm{Cre}^{-}$; $n=11$ cells from 3 mice for each group; Fig. $7 D$ ) remained intact. Thus, autophagy in presynaptic neurons is essential for the size of synaptic vesicle pools in vivo.

Together, these findings indicate that the basal activity of autophagy in presynaptic neurons restricts the number of synaptic vesicles.

\section{Trafficking of synaptic vesicles to autophagosomes}

To explore how autophagy regulates synaptic vesicle pools, we examined whether synaptic vesicles can be recruited to autophagosomes. Primary hippocampal neurons (DIV17) were incubated with an antibody against the luminal domain of the 
A

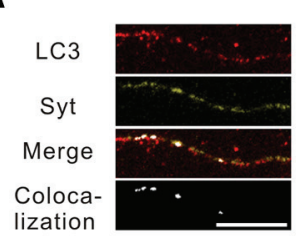

B

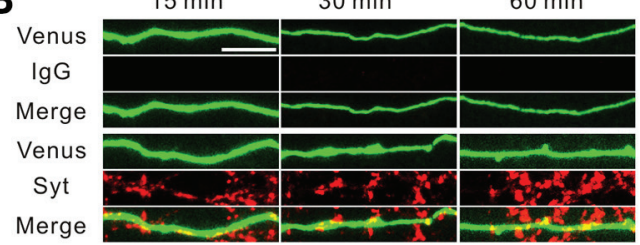

C

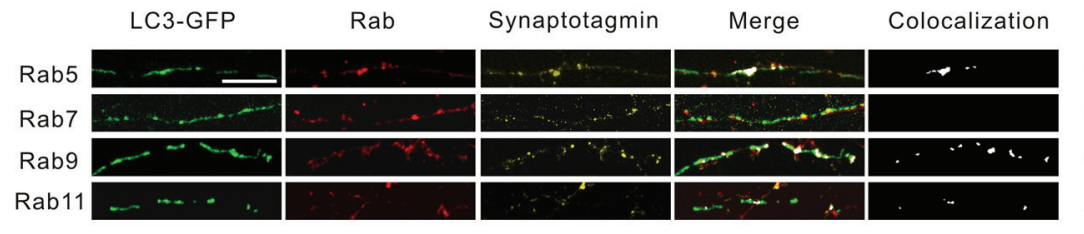

E

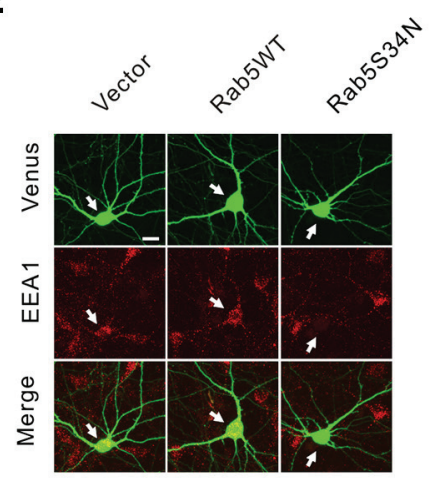

F

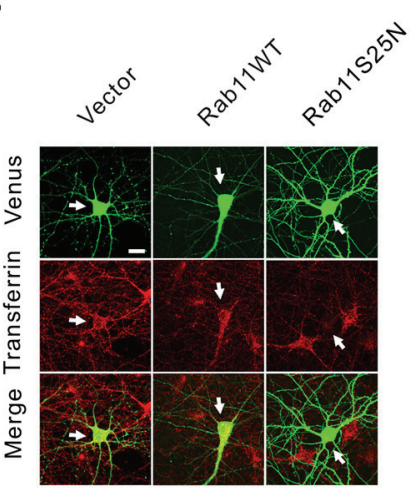

D

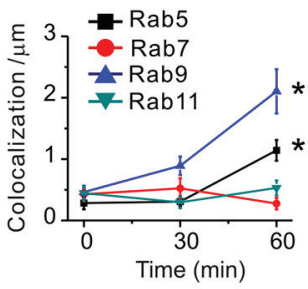

G

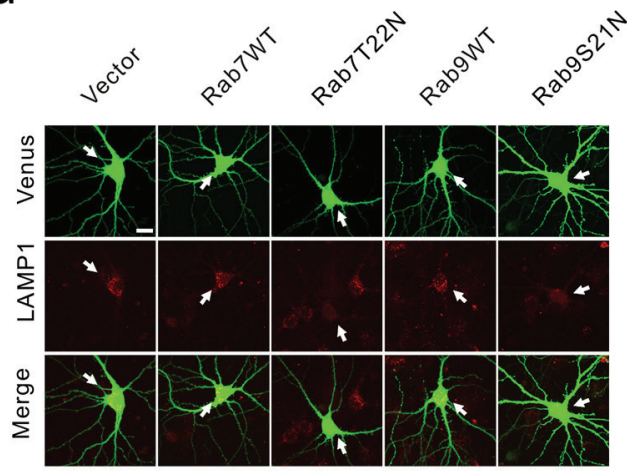

H

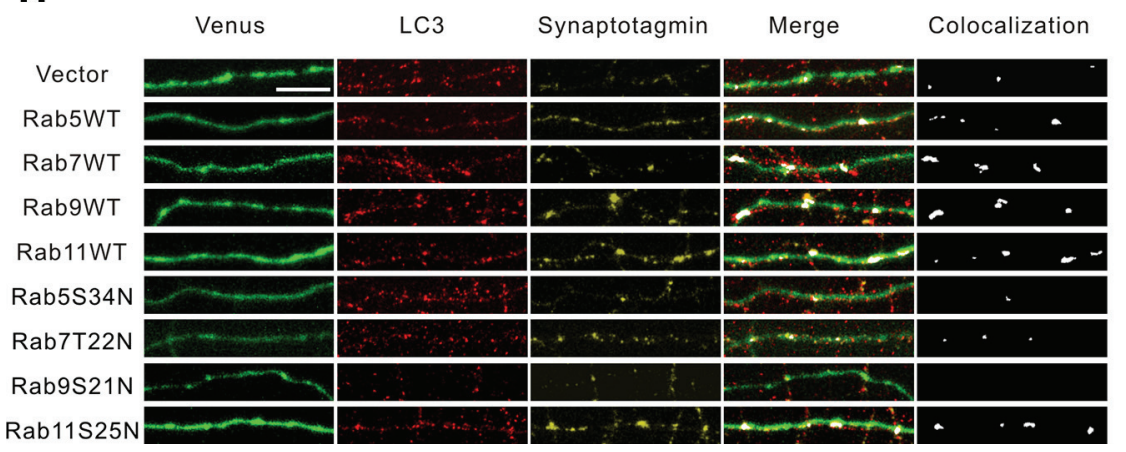

I

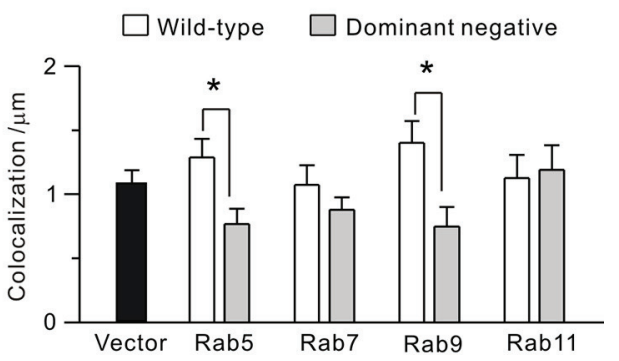

Figure 8. Trafficking of synaptic vesicles to autophagosomes. Cultured hippocampal neurons (DIV17, untransfected in $\boldsymbol{A}$, or transfected with Venus in $\boldsymbol{B}$, or EGFP-tagged LC3 in C,D, or Rabs in $\boldsymbol{E}-\boldsymbol{I})$ were incubated with an antibody against the luminal domain of synaptotagmin 1 and stained with the anti-LC3 antibody $(\boldsymbol{A}, \boldsymbol{H}, \boldsymbol{I})$, or anti-Rab $(\boldsymbol{C}, \boldsymbol{D})$ antibody. $\boldsymbol{A}$, Representative images of axons after feeding with the synaptotagmin antibody. $\boldsymbol{B}$, Representative images of axons after feeding with the synaptotagmin antibody. Cells were fixed at 15,30 , or 60 min after incubation with the synaptotagmin antibody or IgG. C, Representative images of axons from transfected neurons that were fixed at 60 min after feeding with the synaptotagmin antibody. $\mathbf{D}$, Quantification of Rab, LC3, and synaptotagmin colocalization for C. E-G, The effect of DN Rab GTPases on endosomes in cultured hippocampal neurons (DIV17, $3 \mathrm{~d}$ after transfection with constructs expressing WT or DN Rab GTPases along with the Venus construct). Arrows indicate transfected neurons. $\boldsymbol{H}$, Representative images of axons from transfected neurons that were fixed at $60 \mathrm{~min}$ after live labeling with the synaptotagmin antibody. $I$, Quantification of puncta doubly positive for LC3 and synaptotagmin. $n=10-12$ neurons for each group. Data are mean \pm SEM. Mann-Whitney $U$ test was used for computing $p$ values. $* p<0.05$. Scale bars: $A, B, C, H, 10 \mu \mathrm{m} ; E-G, 20 \mu \mathrm{m}$.

synaptic vesicle protein synaptotagmin 1 to label endocytosed synaptic vesicles, then fixed and stained with the LC3 antibody. The specificity of synaptotagmin staining was tested by using nonspecific antibodies (IgG). No fluorescent signals were detected in cells incubated with IgG (Fig. 8B). Some synaptotagmin antibody-stained puncta in axons were positive for LC3 (Fig. 8A), suggesting that endocytosed synaptic vesicles can be delivered to autophagosomes.

Because endosomal sorting is an important step in synaptic vesicle cycling (Sudhof, 2004; Hoopmann et al., 2010; Uytterhoeven et al., 2011), we examined whether the endosomal system is involved in the trafficking of synaptic vesicles to autophagosomes. Cultured hippocampal neurons (DIV14) were transfected with a construct expressing GFP-tagged LC3 (for visualization of autophagosomes). At $3 \mathrm{~d}$ after transfection, the antibody against the luminal domain of synaptotagmin was added to the medium to label endocytosed synaptic vesicles. Neurons were then fixed for staining with antibodies against the early endosome marker Rab5, the late endosome makers Rab7 and Rab9, and the recycling endosome marker Rab11 
(Zerial and McBride, 2001; Yap and Winckler, 2012) at 0, 30, and 60 min after antibody feeding.

During the post-antibody-feeding period, the number of Rab5, LC3, and synaptotagmin colocalized puncta increased (Fig. 8C,D). Likewise, the number of puncta positive for Rab9, LC3, and synaptotagmin also increased over time (Fig. 8C,D). By contrast, the number of puncta containing LC3 and synaptotagmin along with Rab7 or Rab11 remained unchanged. These results suggest that synaptic vesicles can be recruited to autophagosomes, at least in part, through early endosomes and Rab9containing late endosomes.

In addition to being endosomal markers, Rab GTPases are also important regulators of vesicular trafficking (Barbero et al., 2002; Sudhof, 2004; Yap and Winckler, 2012). To test whether they are involved in the transport of synaptic vesicles to autophagosomes, we generated constructs expressing dominant negative (DN) mutants of Rab (Rab5S34N, Rab7T22N, Rab9S21N, and Rab11S25N). These DN mutants caused decreases in endosomes (early endosomes by DN-Rab5, recycling endosomes by DN-Rab11, and late endosomes by DN-Rab7 and DNRab9; Fig. 8E-I).

Hippocampal neurons were transfected with WT or DN Rabs, fed with the antibody against the luminal domain of synaptotagmin, and then stained with the LC3 antibody. In both DNRab5 and DN-Rab9 transfected cells, the number of synaptotagmin and LC3 colocalized puncta was reduced compared with cells transfected with the empty vector (Fig. $8 E-I$ ). By contrast, transfection of constructs expressing DN-Rab7, DN-Rab11, or WT Rab5, Rab9, Rab7, or Rab11 had no effect on the colocalization of synaptotagmin and LC3 (Fig. 8E-I).

Together, these results show that synaptic vesicles can be recruited to autophagosomes via early and late endosomes.

\section{Autophagy influences the turnover of synaptic vesicle pools induced by synaptic activation}

The number of synaptic vesicles is reduced following synaptic excitation which induces exocytosis of synaptic vesicles. After exocytosis, vesicles are retrieved by endocytosis for recycling and synaptic vesicle pools are replenished (Sudhof, 2004). Having found that autophagy controls the basal level of synaptic vesicle number, we proceeded to test whether it influences the dynamic change of synaptic vesicle pools after synaptic excitation. We first tested whether autophagy is regulated by synaptic activity. Primary hippocampal neurons (DIV14) were transfected with a construct expressing $\beta$-galactosidase for visualization of neuronal morphology. At $3 \mathrm{~d}$ after transfection, neurons were depolarized with $60 \mathrm{~mm} \mathrm{KCl}$ for $2 \mathrm{~min}$, then stained for Bassoon (to identify synapses) and LC3. Following depolarization, the number of LC3 and Bassoon colocalized puncta was reduced (Fig. $9 A, C)$. We also stained neurons with DEVD-biotin to label active caspase-3 (Li et al., 2010), and detected an increase in DEVD staining in depolarized axons (Fig. 9B,D). This increase in DEVD staining was abolished in neurons preincubated with unconjugated DEVD-fmk (Fig. 9B,D), confirming that it was because of elevated caspase-3 activity. Likewise, DEVD treatment also blocked depolarization-induced reduction of autophagy in presynaptic terminals (Fig. 9A,C). These results indicate that autophagy at the presynaptic terminal is inhibited by neural depolarization via caspase-3.

To test for the effect of autophagy suppression during neural activation on synaptic vesicles, we measured the depletion and recovery of synaptic vesicle pools in hippocampal slices following high-frequency stimulation. A train of 150 pulses at $10 \mathrm{~Hz}$ was delivered to the Schaffer collateral pathway in hippocampal slices to deplete synaptic vesicles. fEPSPs were recorded in the CA1 region during and at 250-5000 ms after stimulation. We estimated the rate of synaptic vesicle depletion from the fEPSP decay curve derived by plotting normalized fEPSP slopes against time. In WT slices, fEPSPs decayed with a decay constant of $7.09 \pm 0.39 \mathrm{~s}(n=8$ cells from 3 mice $)$, while in slices treated with rapamycin, fEPSP decay was accelerated $[5.20 \pm 0.36 \mathrm{~s}$, $n=8$ slices from 3 mice; one-way ANOVA was used for comparison across groups, $F_{(4,35)}=3.454, p=0.018$; Student-Newman-Keuls method for post hoc analysis, $p=0.018$ for rapamycin vs WT; Fig. $9 E]$. Likewise, in BAD, BAX, and caspase-3 KO hippocampal slices which had elevated autophagy (Figs. $3 C, D, 4 C, D$ ), fEPSPs also decayed faster than in WT slices (BAD KO: $5.05 \pm 0.70 \mathrm{~s}, p=0.028$ for BAD KO vs WT; BAX KO, $5.58 \pm 0.36 \mathrm{~s}, p=0.027$ for BAX KO vs WT; caspase- $3 \mathrm{KO}, 5.07 \pm 0.41 \mathrm{~s}, p=0.02$ for caspase- $3 \mathrm{KO}$ vs WT; $n=8$ slices from 3 mice; Fig. $9 E$ ).

We estimated the recovery rate of synaptic vesicle pools from fEPSPs recorded during $250-5000 \mathrm{~ms}$ after the $10 \mathrm{~Hz}$ stimulation. Rapamycin treatment decreased the recovery rate of fEPSPs (untreated: $17.68 \pm 1.70 \%$ per second; rapamycintreated: $10.97 \pm 0.99 \%$ per second; $n=9$ or 10 slices from 3 mice for each group; one-way ANOVA on ranks was used for comparison across groups, $\mathrm{H}_{4}=13.485, p=0.009$; Dunn's method was used for post hoc analysis, $p=0.026$; Fig. $9 F$ ). The recovery rate was also slower in $\mathrm{KO}$ slices [BAD KO: $11.16 \pm 1.26 \%$ per second, $p=0.006$ for $\mathrm{BAD} \mathrm{KO}$ vs WT; BAX KO: $11.73 \pm 1.78 \%$ per second, $p=0.015$ for $\mathrm{BAX} \mathrm{KO}$ vs WT; caspase-3 KO: $11.23 \pm 0.86 \%$ per second, $p=0.042$ for caspase- $3 \mathrm{KO}$ vs WT; $n=9$ or 10 slices from 3 mice; oneway ANOVA ( $\mathrm{H} 4=13.485, p=0.009)$ for comparison across groups; Dunn's method for post hoc analysis; Fig. $9 F$ ].

Together, these findings suggest that autophagy is suppressed during synaptic activation and that the autophagy inhibition delays the depletion and facilitates the recovery of synaptic vesicle pools.

\section{Autophagy is suppressed during fear conditioning to facilitate associative fear learning and memory}

Synaptic transmission is essential for cognitive processing and behavior. Given our finding that autophagy regulates the kinetics of activity-induced synaptic vesicle cycling in hippocampal neurons, we tested whether autophagy is involved in hippocampusdependent behaviors. As hippocampal neurons are activated during associative learning and are essential for associative learning and memory (Maren et al., 2013), we examined fear conditioning (a hippocampus-dependent, associative learning paradigm eliciting robust associative fear memory) in CA3-specific Atg5 KO mice (9-10 weeks of age). Mice were placed in a fear-conditioning chamber, allowed $2 \mathrm{~min}$ to become familiarized with the novel environment, and then received foot shock (US) paired with auditory CS. The US-CS pairing was repeated 5 times. Both WT $\left(\mathrm{Cre}^{-}\right)$and $\mathrm{KO}\left(\mathrm{Cre}^{+}\right)$mice exhibited a progressive increase in fear response (freezing) following CS-US pairings (Fig. 10A). KO mice; however, spent more time in freezing (Fig. 10A), indicating that their fear learning is enhanced.

One day after fear conditioning, mice received CS without being paired with US for testing of fear memory. KO mice spent more time in freezing than WT mice during the presentation of CS $(p=0.008$, two-tailed Student's $t$ test; Fig. $10 B)$, indicating that their fear memory is enhanced. This is not caused by elevated innate fear or impaired locomotor activity, because their behavior in the light/dark box and elevated zero maze (assessing 
A

LC3

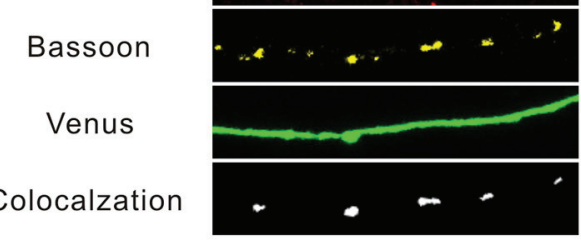

B

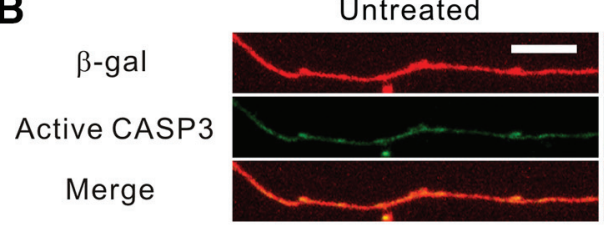

C

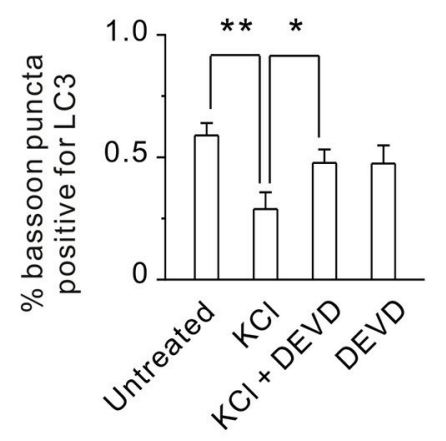

$\mathrm{KCl}$

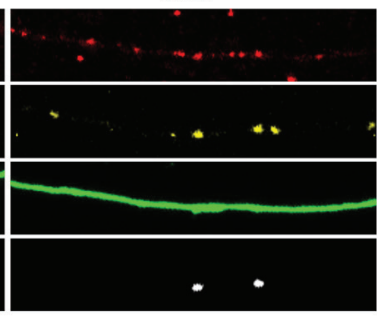

$\mathrm{KCl}$

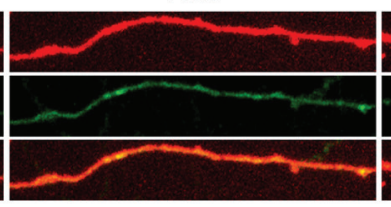

$\mathrm{KCl}+\mathrm{DEVD}$

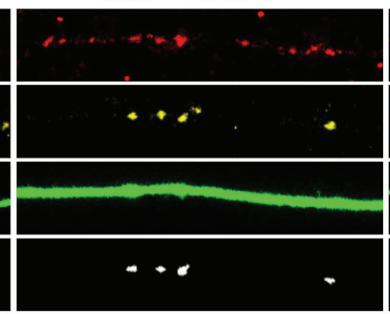

$\mathrm{KCl}+\mathrm{DEVD}$

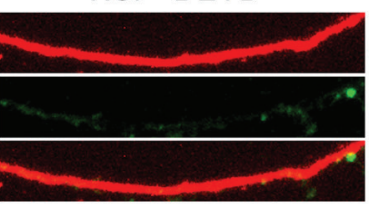

DEVD

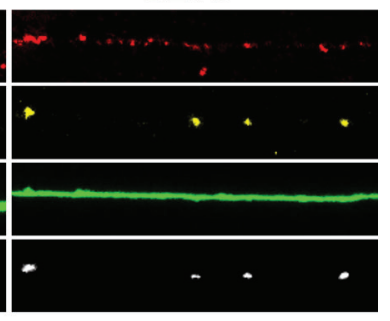

DEVD

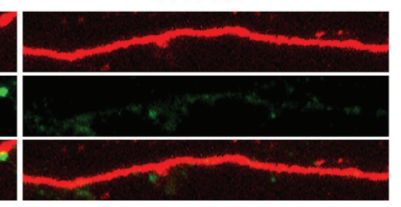

\section{E}

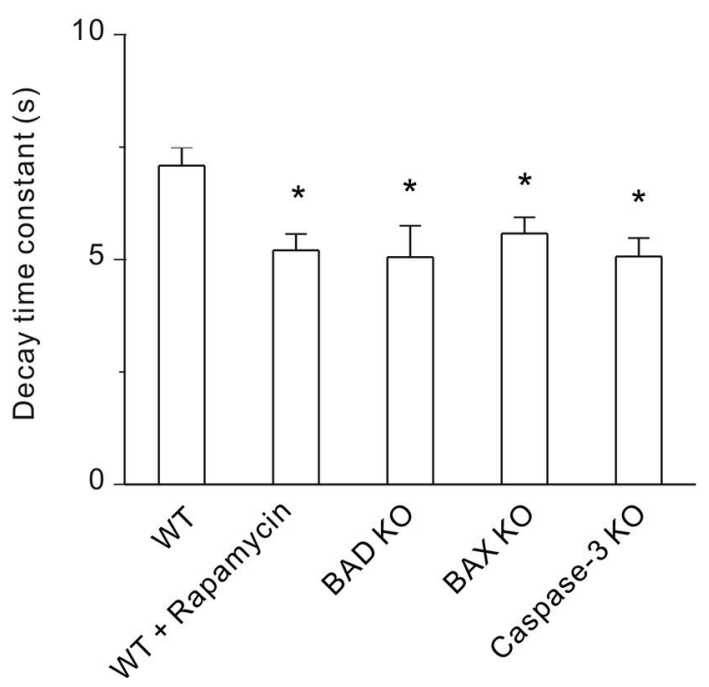

D

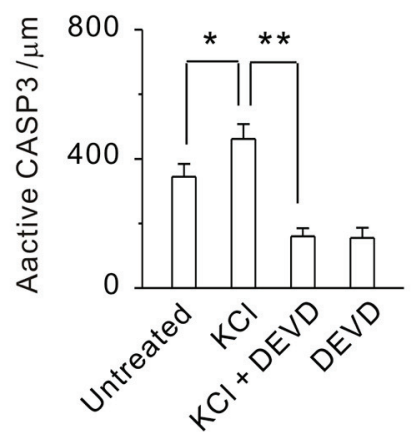

F

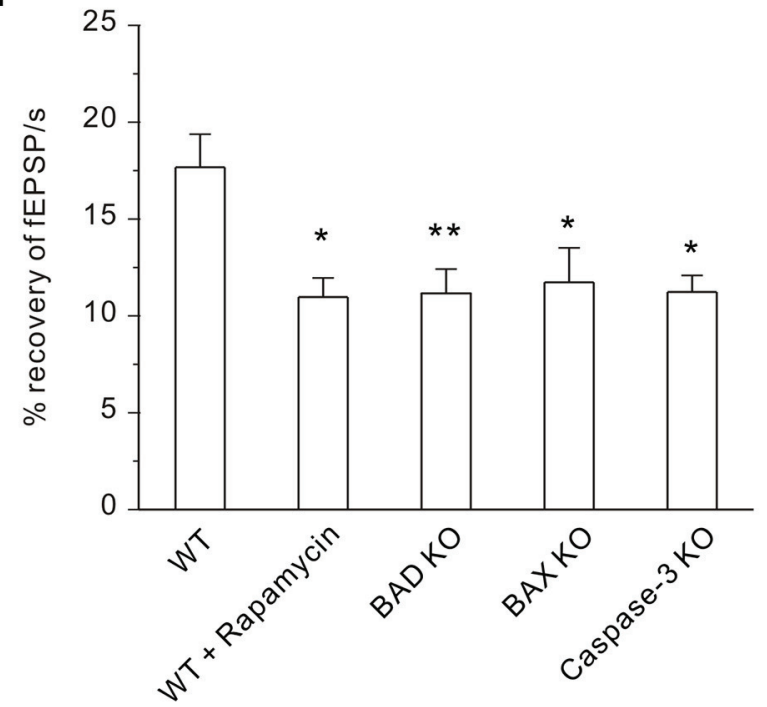

Figure 9. Activity-dependent regulation of autophagy by caspase-3 and the impact of this regulation on presynaptic release in response to intense stimulation. Cultured hippocampal neurons (DIV14) were transfected with the $\beta$-galactosidase or Venus construct for visualization of axons. Two days later, cells were treated with vehicle or the caspase-3 inhibitor DEVD-fmk (10 $\mu \mathrm{m}$ ) for $30 \mathrm{~min}$, then treated with $60 \mathrm{~mm} \mathrm{KCl}$ for 2 min and stained with antibodies as indicated $(\boldsymbol{A}-\boldsymbol{D})$. $\boldsymbol{A}$, Representative images of transfected axons (green) stained with antibodies against Bassoon (yellow) and LC3 (red). B, Representative images of transfected axons (red) stained with active caspase-3 (green). C, Proportion of puncta costained by the Bassoon and LC3 antibodies in Bassoon-positive puncta. $n=10-12$ neurons for each group in $\boldsymbol{A}-\boldsymbol{D}$. $\boldsymbol{D}$, Integrated fluorescence intensity of active caspase-3 normalized to the length of axon. $\boldsymbol{E}, \boldsymbol{F}$, Hippocampal slices were prepared from WT and BAX KO mice, and stimulated (150 pulses delivered at $10 \mathrm{~Hz}$ ) at the Schaffer collateral pathway for field recordings in the CA1 area. $E$, The decay time constant of fEPSPS during stimulation. $\boldsymbol{F}$, The recovery rate of fEPSPs following stimulation. $n=9-11$ slices from 2 or 3 animals for each group in $\boldsymbol{E}, \boldsymbol{F}$. Scale bars: $\boldsymbol{A}, \boldsymbol{B}, 10 \mu \mathrm{m}$. Data are mean \pm SEM. MannWhitney $U$ test was used for computing $p$ values. $* p<0.05$. $* * p<0.01$.

innate fear), and an open field (assessing locomotion) was comparable to that of WT mice (Fig. 10C-E). These results indicate that autophagy constrains associative fear learning and memory.
Since fear conditioning engages hippocampal synapses, we tested whether associative learning alters autophagic flux by subjecting CA1-specific Atg5 $\mathrm{KO}$ mice to fear conditioning and removed their hippocampi immediately after CS-US pairings. 

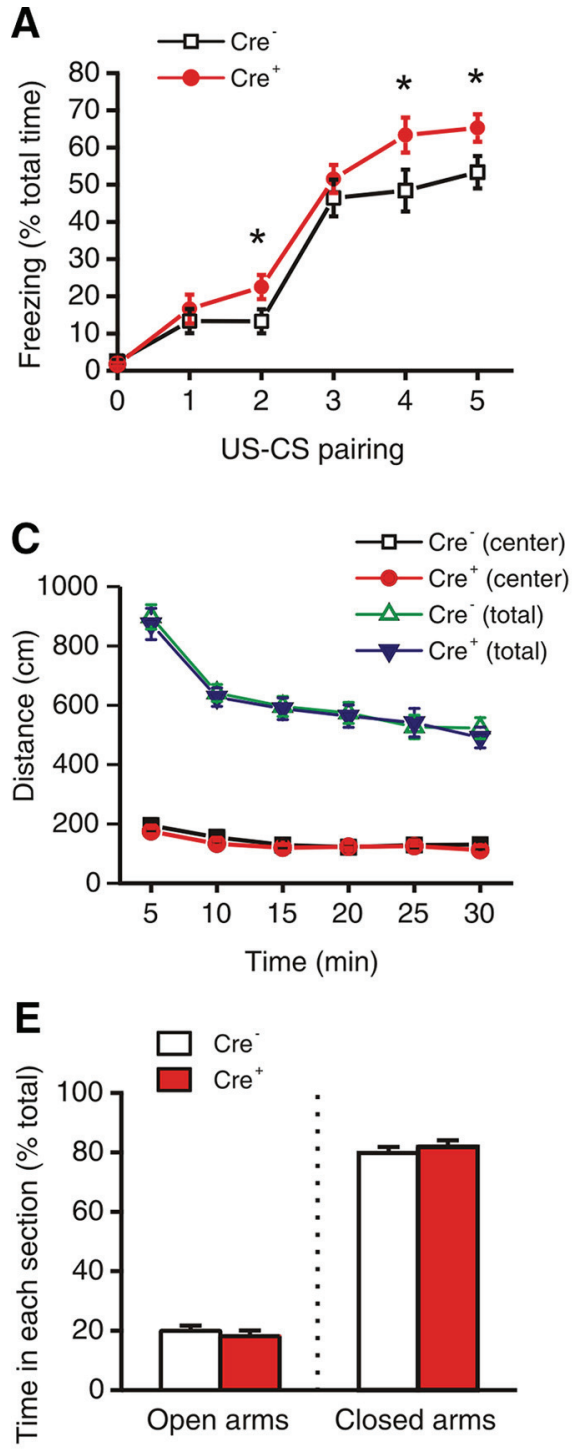

B
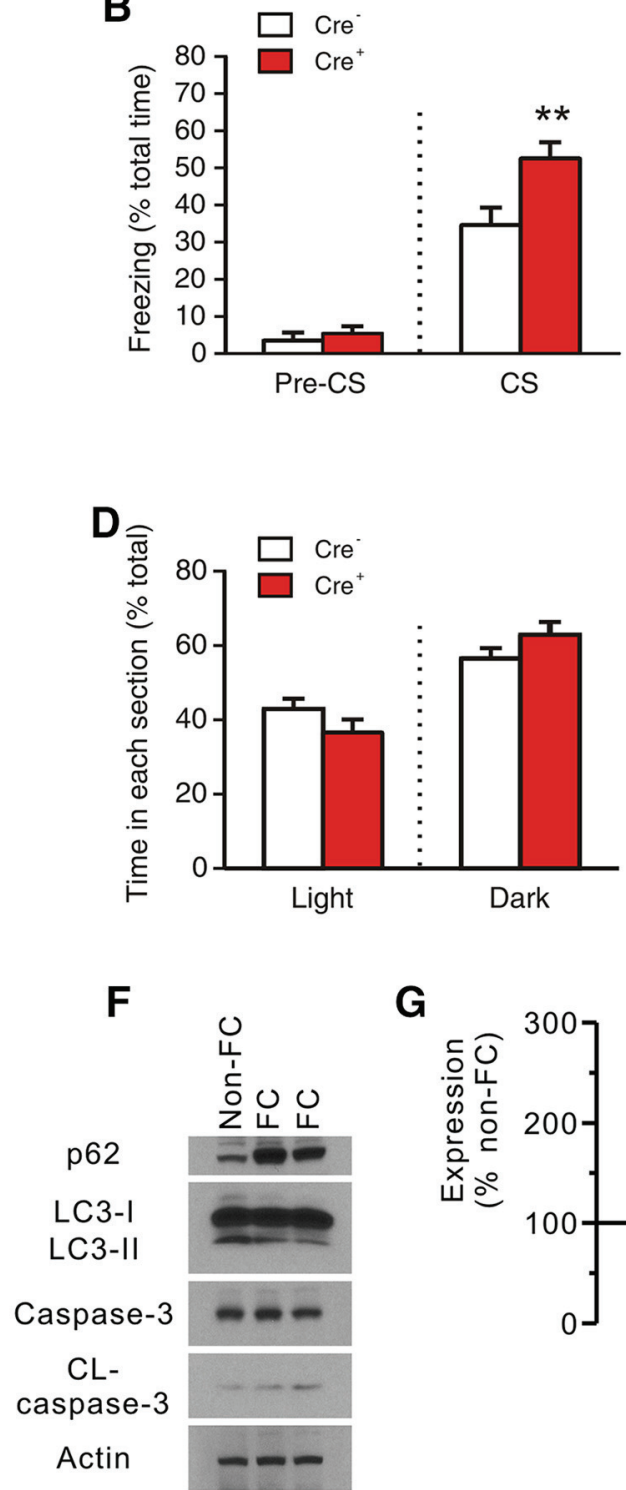

G

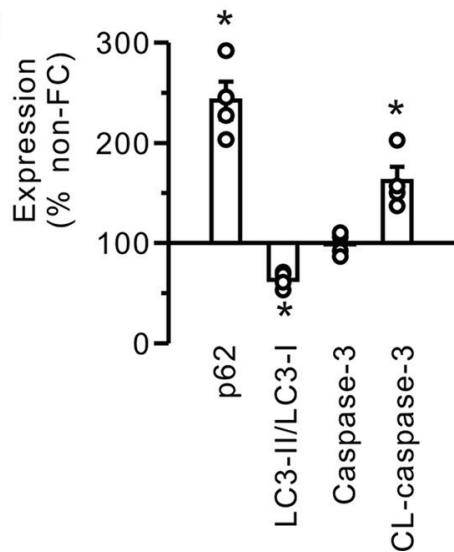

Figure 10. Autophagy is suppressed in fear conditioning to facilitate associative fear learning and memory. $\boldsymbol{A}-\boldsymbol{E}$, CA3-specific Atg5 KO mice and their WT littermates (9-10 weeks of age) were trained with fear conditioning $(\boldsymbol{A}, \boldsymbol{B})$ or analyzed using the open field $(\boldsymbol{C})$, light/dark box $(\boldsymbol{D})$, or elevated zero maze $(\boldsymbol{E})$ test. $\boldsymbol{F}, \mathbf{G}, \mathbf{C A 1}$-specific Atg5 K0 mice and their WT littermates (910 weeks of age) were trained with fear conditioning, and the hippocampus was removed after fear conditioning for immunoblotting. $A$, Freezing response following each CS-US pairing during fear conditioning; $n=23$ mice for each genotype. $B$, Freezing time before and during $C S$ delivery at $1 \mathrm{~d}$ after fear conditioning; $n=23$ mice for each genotype. Mann-Whitney $U$ test was used for pre-CS, and two-tailed Student's $t$ test was used for CS. C, Distance traveled in the open field during each 5 min block; $n=19$ mice for each genotype. D, Time spent in the light and dark compartments in the light/dark box test; $n=19$ mice for each genotype. $\boldsymbol{E}$, Time spent in the open and enclosed arms in the elevated zero maze test; $n=19$ mice for each genotype. $\boldsymbol{F}$, Representative immunoblots of the hippocampus removed after fear conditioning (FC). $G$, Quantification of $F ; n=5$ for non- $F($ and $n=4$ for $F($ mice. Mann-Whitney $U$ test was used for comparison of $\mathrm{FC}$ versus non-FC. Data are mean $\pm \mathrm{SEM} . * p<0.05 . * * p<0.01$.

We used CA1-specific Atg5 KO mice because their Atg5 protein expression and autophagy were impaired in the CA1 region (Fig. $7 A, B)$ so that we can measure autophagic flux in extra-CA1 (including CA3) regions of the hippocampus. Fear conditioning decreased LC3-II and increased p62 (Fig. 10F,G). Moreover, while the total level of caspase- 3 proteins remained intact, active (cleaved) caspase- 3 was increased by fear conditioning (Fig. 10F, $G)$. These changes in active caspase- 3 and autophagy are consistent with our finding that caspase- 3 inhibits autophagic flux in hippocampal neurons (Fig. $3 C, D$ ). Hence, fear conditioning attenuates autophagy presumably by activating caspase-3.

Together, these findings indicate that the caspase-autophagy pathway in CA3 neurons facilitates associative fear learning and memory.

\section{Discussion}

In this study, by using KO mice deficient for caspase- 3 activation and manipulating autophagy with pharmacological, molecular and genetic approaches, we show that the size of synaptic vesicle pools is controlled by autophagy in presynaptic neurons and that autophagy is regulated by the BAD-BAX-caspase- 3 cascade. This BAD-BAX-caspase-autophagy pathway is important for maintaining and renewing pools of synaptic vesicles, learning, and memory.

The BAD-BAX-caspase-3 cascade, which is a canonical apoptosis pathway, plays a nonapoptotic role in long-term synaptic depression at the postsynaptic site ( $\mathrm{Li}$ et al., 2010; Jiao and $\mathrm{Li}$, 2011). Several lines of evidence from this study indicate that 
independent of its postsynaptic role, the BAD-BAX-caspase- 3 cascade is also a key regulator of presynaptic properties. First, although mEPSC frequency and PPR are altered in BAD, BAX, and caspase- $3 \mathrm{KO}$ mice, normal mEPSC amplitude suggests that postsynaptic neurotransmitter receptors remain intact. Second, both electrophysiological and electron microscopy assays reveal deficiencies in synaptic vesicles in BAD, BAX, and caspase-3 $\mathrm{KO}$ mice. Last and importantly, knocking Atg proteins down or out in presynaptic, but not in postsynaptic neurons, causes changes in synaptic vesicle pools.

In addition to smaller synaptic vesicle pools, we also find that $\mathrm{BAD}, \mathrm{BAX}$, and caspase-3 KO neurons have fewer synapses. This decrease in synapse number can also contribute to lower mEPSC frequency. Our finding that mitochondrial number and content at presynaptic sites are unchanged in $\mathrm{KO}$ mice suggests that the change in synapse number may be unrelated to mitochondria which influence synapse density (Li et al., 2004). The proportion of mEPSC frequency decrease that is attributable to synapse number and RRP size in $\mathrm{BAD}, \mathrm{BAX}$, and caspase- $3 \mathrm{KO}$ mice could potentially be addressed by such future studies as examining mEPSCs in CA3-specific Atg5 and Atg7 KO mice.

In the hippocampus of caspase- $3 \mathrm{KO}$ mice, there is an increase in several Atg proteins, including Atg-3, -4, -7, -9, and Beclin-1, as well as in the number of autophagosome-like structures. In the hippocampal tissue lysate of BAD and BAX KO mice; however, neither active caspase-3 nor Atg proteins are affected. Separate analyses of neurons and glia from BAD and BAX KO mice show that the reduction of active caspase- 3 and elevation of Atg proteins occur only in neurons and not in glia, suggesting that, in tissue lysates of BAD and BAX KOs, glial cells mask neuronal changes in caspase-3 and Atg proteins. As earlier studies show that several Atg proteins can be cleaved by caspase3 in vitro (Norman et al., 2010), their increases in the KO mice can result from diminished proteolysis by caspase- 3 .

Why do caspase-3 and Atg proteins react differently to BAD and BAX KO in different cell types? In hippocampal and cortical neurons, $\mathrm{BAX}$ is the only $\mathrm{Bcl}-2$ family protein that forms pores on the mitochondria to promote caspase-3 activation downstream of BAD. By contrast, BAK, another pore-forming protein of the Bcl-2 family, is coexpressed with BAX in glia (Sun et al., 2001; Uo et al., 2005). Hence, lack of BAD and BAX has a more severe effect on caspase-3 activation in neurons than in glia. The enhancement of autophagy in $\mathrm{BAD}$ and $\mathrm{BAX} \mathrm{KO}$ neurons further suggests that, in neurons, the crosstalk between autophagy and caspase- 3 is mediated primarily through the mitochondrial pathway of caspase- 3 activation.

We demonstrated that $\mathrm{KO}$ mice deficient in the BAD-BAXcaspase- 3 cascade have more Atg proteins and autophagosomelike structures and that their changes in synaptic vesicle pools were blocked by autophagy inhibitors. These findings suggest that autophagy is responsible for the effect of caspase- 3 activation on synaptic vesicles. By the same token, mTOR inhibitor decreases, while Atg5 KO increases, evoked dopamine release in dopamine neurons (Hernandez et al., 2012). Although the mechanism by which autophagy regulates synaptic transmission in dopamine neurons has yet to be elucidated, our findings raised the possibility that autophagy affects presynaptic release by controlling the number and turnover of synaptic vesicles. Synaptic vesicles are not the only organelles that can be cargos of autophagosomes. Selective autophagy of various organelles, such as mitophagy for mitochondria, ribophagy for ribosomes, pexophagy for peroxisomes, and reticulophagy for endoplasmic reticulum, has been reported (Kundu and Thompson, 2008; He and Klionsky, 2009; Fleming et al., 2011; Youle and Narendra, 2011).
It is possible that the $\mathrm{BAD}-\mathrm{BAX}$-caspase-3 pathway is also involved in other types of organelle autophagy.

What could be the physiological significance of controlling synaptic vesicle pools via the BAD-BAX-caspase-autophagy pathway? Neuronal depolarization activates caspase-3 and suppresses autophagy, thereby delaying synaptic vesicle depletion and accelerating recovery of synapses after intense synaptic stimulation. The caspase-autophagy pathway, therefore, serves to not only ensure the fidelity of synaptic release in response to neural firing, but also enable the coupling of synaptic vesicle numbers to synaptic activity as a means of activity-dependent regulation of synaptic strength. Indeed, modification of synaptic vesicle number has been observed in Hebbian and homeostatic synaptic plasticity (Goda and Stevens, 1998; Vitureira et al., 2012; Rey et al., 2020). Hence, our study suggests that autophagy is not merely a homeostatic mechanism to maintain the integrity of cells and tissues, it is also a process engaged by synaptic excitation to adjust synaptic vesicle pools for an optimal synaptic response. Our behavioral analysis further demonstrates that autophagy-mediated regulation of synaptic release is important for cognitive functions, in that associative fear learning and memory are enhanced in CA3-specific Atg5 KO mice. Hence, the control of synaptic vesicle pools by autophagy is an integral cellular mechanism underlying behavior.

Our study shows the colocalization of some Rab proteins with synaptotagmin and LC3. Different Rab proteins reside in distinct membrane domains and regulate different routes of membrane trafficking (Stenmark, 2009). Rabs on LC3-positive synaptic vesicles, for instance, could be deposited while transiting the synaptic vesicle membrane en route to autophagosomes. Since the LC3-positive synaptic vesicles containing Rab5 (an early endosomal marker) or Rab9 (a late endosomal marker) increase over time after vesicle endocytosis, it appears that synaptic vesicles are transported to autophagosomes via early and late endosomes, a path supported by our finding that DN mutants of Rab5 and Rab9 block autophagic trafficking of synaptic vesicles.

The question then arises as to why there is little colocalization between Rab7, another late endosome marker, and synaptic vesicles positive for LC3, since autophagosomes can acquire Rab7 in axons (Lee et al., 2011). In our study, we only analyzed autophagosomes containing synaptotagmin, but not all autophagosomes. Hence, rather than opposing the role of Rab7 in autophagy, our results suggest that the trafficking of synaptic vesicles to autophagosomes is preferentially through non-Rab7containing endosomal compartments. Indeed, although both Rab7 and Rab9 are considered as markers for late endosomes, they are in distinct endosomal domains (Barbero et al., 2002).

In conclusion, by examining synapses in mice deficient for autophagy and caspase activation, we identified a new pathway for the regulation of synaptic vesicle pools. We also provided evidence that autophagy of synaptic vesicles is essential for determining the probability of presynaptic release, activity-dependent turnover of synaptic vesicle pools, learning, and memory.

\section{References}

Abbott LF, Regehr WG (2004) Synaptic computation. Nature 431:796-803. Barbero P, Bittova L, Pfeffer SR (2002) Visualization of Rab9-mediated vesicle transport from endosomes to the trans-Golgi in living cells. J Cell Biol 156:511-518.

Binotti B, Pavlos NJ, Riedel D, Wenzel D, Vorbruggen G, Schalk AM, Kuhnel K, Boyken J, Erck C, Martens H, Chua JJ, Jahn R (2015) The GTPase Rab26 links synaptic vesicles to the autophagy pathway. Elife 4:e05597.

Bjorkoy G, Lamark T, Brech A, Outzen H, Perander M, Overvatn A, Stenmark H, Johansen T (2005) p62/SQSTM1 forms protein aggregates degraded by autophagy and has a protective effect on huntingtin-induced cell death. J Cell Biol 171:603-614. 
Bourin M, Hascoet M (2003) The mouse light/dark box test. Eur J Pharmacol 463:55-65.

Boya P, Gonzalez-Polo RA, Casares N, Perfettini JL, Dessen P, Larochette N, Metivier D, Meley D, Souquere S, Yoshimori T, Pierron G, Codogno P, Kroemer G (2005) Inhibition of macroautophagy triggers apoptosis. Mol Cell Biol 25:1025-1040.

Catterall WA, Few AP (2008) Calcium channel regulation and presynaptic plasticity. Neuron 59:882-901.

Crawley JN (1999) Behavioral phenotyping of transgenic and knockout mice: experimental design and evaluation of general health, sensory functions, motor abilities, and specific behavioral tests. Brain Res 835:18-26.

Curzon P, Rustay NR, Browman KE (2009) Cued and contextual fear conditioning for rodents. In: Methods of behavior analysis in neuroscience (BuccafuscoJJ, ed). Boca Raton, FL: CRC.

Dobrunz LE, Stevens CF (1997) Heterogeneity of release probability, facilitation, and depletion at central synapses. Neuron 18:995-1008.

Fleming A, Noda T, Yoshimori T, Rubinsztein DC (2011) Chemical modulators of autophagy as biological probes and potential therapeutics. Nat Chem Biol 7:9-17.

Galluzzi L, Pietrocola F, Levine B, Kroemer G (2014) Metabolic control of autophagy. Cell 159:1263-1276.

Ganley IG, Lam du H, Wang J, Ding X, Chen S, Jiang X (2009) ULK1. ATG13.FIP200 complex mediates mTOR signaling and is essential for autophagy. J Biol Chem 284:12297-12305.

Goda Y, Stevens CF (1998) Readily releasable pool size changes associated with long term depression. Proc Natl Acad Sci USA 95:1283-1288.

Hara T, Takamura A, Kishi C, Iemura S, Natsume T, Guan JL, Mizushima N (2008) FIP200, a ULK-interacting protein, is required for autophagosome formation in mammalian cells. J Cell Biol 181:497-510.

Harris KM, Sultan P (1995) Variation in the number, location and size of synaptic vesicles provides an anatomical basis for the nonuniform probability of release at hippocampal CA1 synapses. Neuropharmacology 34:1387-1395.

Hascoet M, Bourin M (1998) A new approach to the light/dark test procedure in mice. Pharmacol Biochem Behav 60:645-653.

He C, Klionsky DJ (2009) Regulation mechanisms and signaling pathways of autophagy. Annu Rev Genet 43:67-93.

Hernandez D, Torres CA, Setlik W, Cebrian C, Mosharov EV, Tang G, Cheng HC, Kholodilov N, Yarygina O, Burke RE, Gershon M, Sulzer D (2012) Regulation of presynaptic neurotransmission by macroautophagy. Neuron 74:277-284.

Hoopmann P, Punge A, Barysch SV, Westphal V, Buckers J, Opazo F, Bethani I, Lauterbach MA, Hell SW, Rizzoli SO (2010) Endosomal sorting of readily releasable synaptic vesicles. Proc Natl Acad Sci USA 107:19055-19060.

Hu Y, Qu L, Schikorski T (2008) Mean synaptic vesicle size varies among individual excitatory hippocampal synapses. Synapse 62:953-957.

Ichimura Y, Kirisako T, Takao T, Satomi Y, Shimonishi Y, Ishihara N, Mizushima N, Tanida I, Kominami E, Ohsumi M, Noda T, Ohsumi Y (2000) A ubiquitin-like system mediates protein lipidation. Nature 408:488-492.

Jiao S, Li Z (2011) Nonapoptotic function of BAD and BAX in long-term depression of synaptic transmission. Neuron 70:758-772.

Jung CH, Jun CB, Ro SH, Kim YM, Otto NM, Cao J, Kundu M, Kim DH (2009) ULK-Atg13-FIP200 complexes mediate mTOR signaling to the autophagy machinery. Mol Biol Cell 20:1992-2003.

Kabeya Y, Mizushima N, Ueno T, Yamamoto A, Kirisako T, Noda T, Kominami E, Ohsumi Y, Yoshimori T (2000) LC3, a mammalian homologue of yeast Apg8p, is localized in autophagosome membranes after processing. EMBO J 19:5720-5728.

Kabeya Y, Mizushima N, Yamamoto A, Oshitani-Okamoto S, Ohsumi Y, Yoshimori T (2004) LC 3 , GABARAP and GATE16 localize to autophagosomal membrane depending on form-II formation. J Cell Sci 117:2805-2812.

Kundu M, Thompson CB (2008) Autophagy: basic principles and relevance to disease. Annu Rev Pathol 3:427-455.

Lee S, Sato Y, Nixon RA (2011) Lysosomal proteolysis inhibition selectively disrupts axonal transport of degradative organelles and causes an Alzheimer's-like axonal dystrophy. J Neurosci 31:7817-7830.

Levine B, Kroemer G (2008) Autophagy in the pathogenesis of disease. Cell 132:27-42.
Li Z, Okamoto K, Hayashi Y, Sheng M (2004) The importance of dendritic mitochondria in the morphogenesis and plasticity of spines and synapses. Cell 119:873-887.

Li Z, Jo J, Jia JM, Lo SC, Whitcomb DJ, Jiao S, Cho K, Sheng M (2010) Caspase-3 activation via mitochondria is required for long-term depression and AMPA receptor internalization. Cell 141:859-871.

Liu X, Gu QH, Duan K, Li Z (2014) NMDA receptor-dependent LTD is required for consolidation but not acquisition of fear memory. J Neurosci 34:8741-8748.

Maren S, Phan KL, Liberzon I (2013) The contextual brain: implications for fear conditioning, extinction and psychopathology. Nat Rev Neurosci 14:417-428.

Mizushima N, Yamamoto A, Matsui M, Yoshimori T, Ohsumi Y (2004) In vivo analysis of autophagy in response to nutrient starvation using transgenic mice expressing a fluorescent autophagosome marker. Mol Biol Cell 15:1101-1111.

Mizushima N, Yoshimori T, Levine B (2010) Methods in mammalian autophagy research. Cell 140:313-326.

Moreau K, Luo S, Rubinsztein DC (2010) Cytoprotective roles for autophagy. Curr Opin Cell Biol 22:206-211.

Nakazawa K, Quirk MC, Chitwood RA, Watanabe M, Yeckel MF, Sun LD, Kato A, Carr CA, Johnston D, Wilson MA, Tonegawa S (2002) Requirement for hippocampal CA3 NMDA receptors in associative memory recall. Science 297:211-218.

Norman JM, Cohen GM, Bampton ET (2010) The in vitro cleavage of the hAtg proteins by cell death proteases. Autophagy 6:1042-1056.

Petralia RS, Wenthold RJ (1999) Immunocytochemistry of NMDA receptors. Methods Mol Biol 128:73-92.

Rey S, Marra V, Smith C, Staras K (2020) Nanoscale remodeling of functional synaptic vesicle pools in Hebbian plasticity. Cell Rep 30:2006-2017.e2003.

Rizzoli SO, Betz WJ (2005) Synaptic vesicle pools. Nat Rev Neurosci 6:57-69.

Rosenmund C, Stevens CF (1996) Definition of the readily releasable pool of vesicles at hippocampal synapses. Neuron 16:1197-1207.

Schikorski T, Stevens CF (1997) Quantitative ultrastructural analysis of hippocampal excitatory synapses. J Neurosci 17:5858-5867.

Shacka JJ, Klocke BJ, Shibata M, Uchiyama Y, Datta G, Schmidt RE, Roth KA (2006) Bafilomycin A1 inhibits chloroquine-induced death of cerebellar granule neurons. Mol Pharmacol 69:1125-1136.

Shibutani ST, Yoshimori T (2014) A current perspective of autophagosome biogenesis. Cell Res 24:58-68.

Stenmark H (2009) Rab GTPases as coordinators of vesicle traffic. Nat Rev Mol Cell Biol 10:513-525.

Stevens CF (1993) Quantal release of neurotransmitter and long-term potentiation. Cell 72[Suppl]:55-63.

Sudhof TC (2004) The synaptic vesicle cycle. Annu Rev Neurosci 27:509-547.

Sun YF, Yu LY, Saarma M, Timmusk T, Arumae U (2001) Neuron-specific $\mathrm{Bcl}-2$ homology 3 domain-only splice variant of Bak is anti-apoptotic in neurons, but pro-apoptotic in non-neuronal cells. J Biol Chem 276:16240-16247.

Tsien JZ, Huerta PT, Tonegawa S (1996) The essential role of hippocampal CA1 NMDA receptor-dependent synaptic plasticity in spatial memory. Cell 87:1327-1338.

Uo T, Kinoshita Y, Morrison RS (2005) Neurons exclusively express N-Bak, a BH3 domain-only Bak isoform that promotes neuronal apoptosis. J Biol Chem 280:9065-9073.

Uytterhoeven V, Kuenen S, Kasprowicz J, Miskiewicz K, Verstreken P (2011) Loss of skywalker reveals synaptic endosomes as sorting stations for synaptic vesicle proteins. Cell 145:117-132.

Vitureira N, Letellier M, Goda Y (2012) Homeostatic synaptic plasticity: from single synapses to neural circuits. Curr Opin Neurobiol 22:516-521.

Yap CC, Winckler B (2012) Harnessing the power of the endosome to regulate neural development. Neuron 74:440-451.

Youle RJ, Narendra DP (2011) Mechanisms of mitophagy. Nat Rev Mol Cell Biol 12:9-14.

Zerial M, McBride H (2001) Rab proteins as membrane organizers. Nat Rev Mol Cell Biol 2:107-117.

Zucker RS, Regehr WG (2002) Short-term synaptic plasticity. Annu Rev Physiol 64:355-405. 